University of San Diego

Digital USD

2011-12-01

\title{
Call-Shift Fatigue and Use of Countermeasures and Strategies by Certified Registered Nurse Anesthetists
}

Ramona M. Domen PhD, CRNA

University of San Diego

Follow this and additional works at: https://digital.sandiego.edu/dissertations

Part of the Nursing Commons

\section{Digital USD Citation}

Domen, Ramona M. PhD, CRNA, "Call-Shift Fatigue and Use of Countermeasures and Strategies by Certified Registered Nurse Anesthetists" (2011). Dissertations. 419.

https://digital.sandiego.edu/dissertations/419

This Dissertation: Open Access is brought to you for free and open access by the Theses and Dissertations at Digital USD. It has been accepted for inclusion in Dissertations by an authorized administrator of Digital USD. For more information, please contact digital@sandiego.edu. 


\title{
UNIVERSITY OF SAN DIEGO
}

Hahn School of Nursing and Health Science

DOCTOR OF PHILOSOPHY IN NURSING

CALL-SHIFT FATIGUE AND USE OF COUNTERMEASURES AND STRATEGIES

BY

CERTIFIED REGISTERED NURSE ANESTHETISTS

by

Ramona M. Domen, CRNA

A dissertation presented to the

FACULTY OF THE HAHN SCHOOL OF NURSING AND HEALTH SCIENCE UNIVERSITY OF SAN DIEGO

\author{
In partial fulfillment of the \\ requirements for the degree of
}

DOCTOR OF PHILOSOPHY IN NURSING

December 2011

Dissertation Committee

Cynthia D. Connelly, PhD, RN, FAAN, Chairperson

Andrea L. Hazen, $\mathrm{PhD}$

Dennis L. Spence, PhD, CRNA

UNIVERSITY OF SAN DIEGO 


\begin{abstract}
Purpose: The purpose of this study was to examine whether Certified Registered Nurse Anesthetists (CRNAs) experience fatigue during call and to assess their use of fatigue avoidance strategies (practices that prevent fatigue) and fatigue countermeasures (practices that decrease fatigue) to mitigate its effects.
\end{abstract}

Method: Using a cross sectional descriptive survey design, data were collected from a randomly selected sample of 323 practicing CRNAs who worked call shifts.

Data analysis: Data were analyzed using descriptive and multivariate statistics.

Results: The sample was fairly evenly distributed with slightly more female respondents, $55 \%(n=179)$. Fifty four percent worked a weekday call of $\leq 16$ hours; $75 \%$ worked weekend shifts $>17$ hours. Nearly $43 \%$ described fatigue occurring 'often' (nearly every call), or 'frequent' (once/month), and 57\% as 'occasional' (4 times/year), or 'rare' (once/year). Of 91 CRNAs who reported a patient care error, 63\% reported frequent fatigue. The theory of unpleasant symptoms (Lenz et al., 1997) provided a conceptual pathway for fatigue influences: physiologic, psychological, and situational factors that can lead to health symptoms and affect performance. Open-ended descriptions of interventions were coded as physiologic, psychological, or situational tactics. 'Fatigue prevention' (sleeping longer, napping before call), was the primary fatigue avoidance strategy, while 'nutrition' (i.e. snacks, caffeine, etc.) was the primary fatigue countermeasure. Logistic regression results indicate the overall model of eight predictors was statistically reliable in distinguishing status of fatigue experience $(-2$ Log Likelihood $=385.08 ;$ Goodness of Fit $=3.59 ; \chi 2(10)=49.06, p=.000)$. Wald statistics indicate weekend call duration, fatigue avoidance strategy use, number of fatigue 
countermeasures used, and number of anesthesia days per week was significant in predicting fatigue status.

Conclusion: This study presents findings related to the experience of fatigue and challenges the individual practitioner to be aware of fatigue's effect on performance, supports a relationship between healthcare worker fatigue and patient error, and adds to the scientific knowledge regarding the use of fatigue avoidance strategies and countermeasures. Fatigue awareness and education programs to promote healthy sleep and alertness should be developed, implemented, and evaluated. 


\section{DEDICATION}

This dissertation is dedicated to all deployed medical personnel of the United States Armed Forces, especially those using their expertise for research to better the treatment and recovery of our fighting forces. To those patients who managed to say thanks, despite their pain and fear, and to the courageous men and women who passed despite our best efforts.

To my parents, John Jr. and Nia who taught me at a very young age growing up on a farm, anything worth doing takes planning, hard work, and dedication. Finally, to my high-school tennis coach, Mr. Stephen Nakano, who expected short and long-term written goals, which I still do today.

Lastly, to my loving husband, Paul Witt, who painstakingly learned the APA format and provided unwavering support from the start through the long finish. 


\section{ACKNOWLEDGEMENTS}

Words cannot express the depth of gratitude I owe to my dissertation chair and Director of Research at the University of San Diego, Cynthia Connelly, Ph.D., R.N., F.A.A.N, for her continued dedication and guidance on a project she did not start, however spent an inordinate amount of time and effort to help produce and finish. I would like to thank my dissertation members CDR Dennis Spence, Ph.D., CRNA, USN, for valuable input, time, and clarity to help realize a better-read final project. Lastly, thanks to the important contributions of Andrea Hazen, Ph.D., for guidance in the overwhelming first step to organize and code eight open-ended questions, as well as statistical input throughout the project.

Acknowledgments go to CDR (Ret., USN) Joseph Burkard, PhD., CRNA, for his commitment at the start of the program, when one single project seemed to be a foreign concept; as well, CDR Lisa Osborne, Ph.D., CRNA, USN, who believed in me before I would ever acknowledge further scholarly work or say " $\mathrm{PhD}$ ".

My sincere thanks to my most influential mentors of the Navy, who challenged my growth while injecting wisdom; displaying the most desired traits in a person and an officer - CAPT (Ret) Joseph Murray, CDR (Ret) Eric Herbert, MD, CAPT R. Lee Olson, CDR (Ret) Joseph Kelly, Melanie Smith, MD, and CAPT Angelica Almonte, Ph.D..

Finally, I thank God, who has seen me through yet another challenge, though this one a bit different, one I believe encourages me to better our healthcare profession. 
DEDICATION ............................................................... ii

ACKNOWLEDGEMENTS ........................................... iii

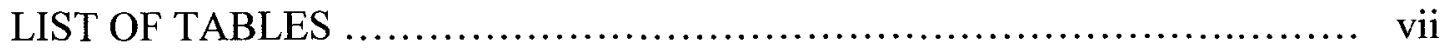

LIST OF FIGURES ..................................................... viii

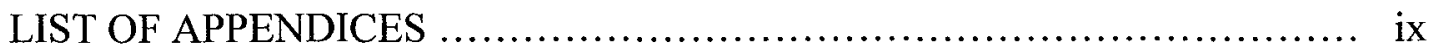

CHAPTER I: INTRODUCTION ............................................ 1

Work Hour Restriction, Mandatory Overtime, and Medical Error.......... 1

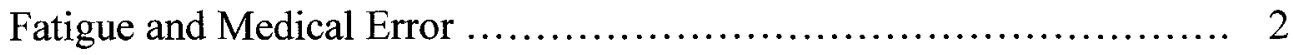

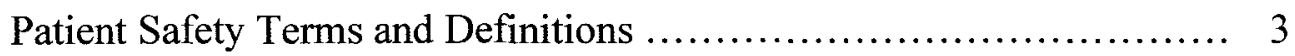

Vigilance and Anesthesia .......................................... 4

Circadian Rhythm, Neurobehavioral Performance and Neuromodulation 5

Countermeasures ............................................... 7

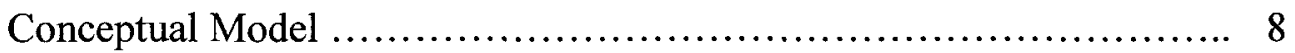

Purpose and Research Aims ...................................... 10

Importance to the Advancement of Nursing Science ................... 10

CHAPTER II: REVIEW OF THE LITERATURE .......................... 12

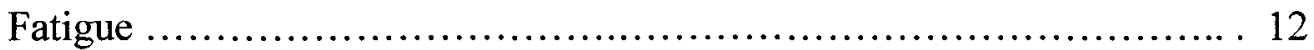

Measurements ........................................................ 13

Physiologic Measurements .................................. 13

Behavioral Measurements .................................... 14 
Performance Observation Measurements ....................... 14

Self-Report Measurements ................................. 15

Fatigue Influences ............................................ 15

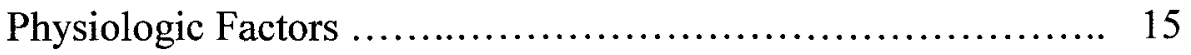

Psychological Factors ..................................... 17

Situational Factors - Performance and Shift Length ............. 20

Vigilance and Anesthesia............................................ 23

Performance During Acute Fatigue - Field Studies ................... 25

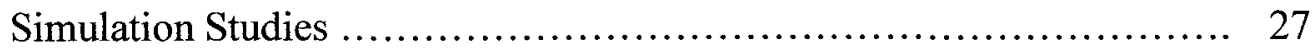

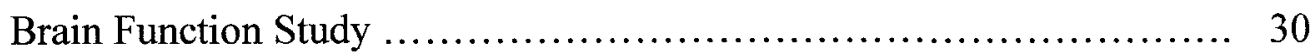

Fatigue Countermeasures in High-Risk Industries .................... 30

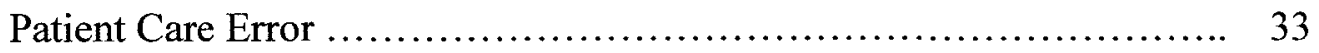

Conceptual Framework ......................................... 34

CHAPTER III: METHODOLOGY ..................................... 37

Methods ........................................................ 37

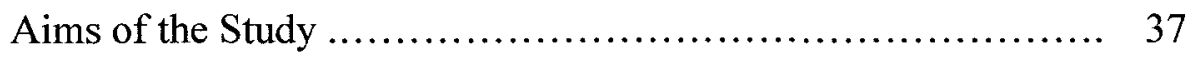

Design ................................................. 38

Procedures ........................................................ 39

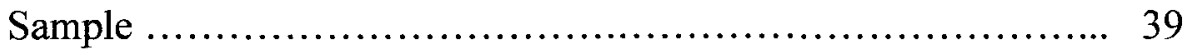

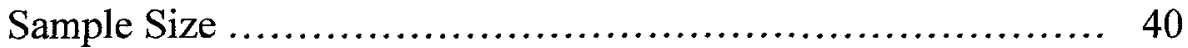

Instrumentation and Data Collection .......................... 40

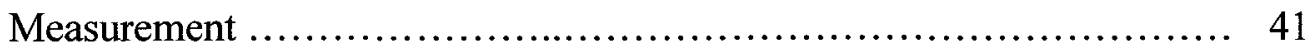


Fatigue

Fatigue avoidance Strategies ............................. 42

Fatigue Countermeasures .................................. 42

Demographics .......................................... 42

Data Collection ................................................. 43

Data Management and Analysis ............................. 43

Protection of Human Subjects ...................................... 48

CHAPTER IV: RESULTS ................................................ 49

Characteristics of the Sample ...................................... 49

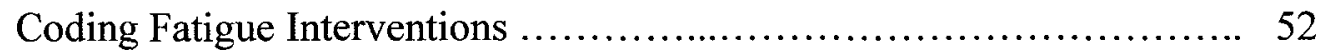

Research Aims and Questions ................................... 57

CHAPTER V: DISCUSSION OF FINDINGS .............................. 63

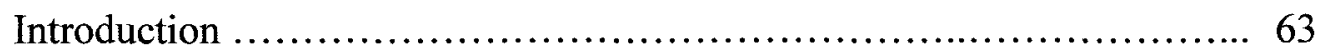

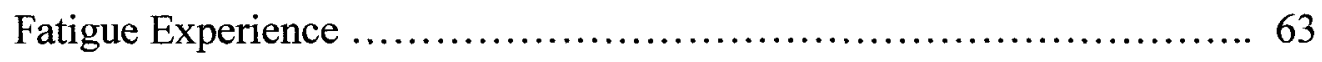

Coding Fatigue Interventions Using the Theoretical Framework .. 64

Interpretations of the Results ...........................................................6 66

Implications for Practice and Education ...................... 70

Limitations ............................................... 72

Recommendations for Research ............................ 72

Policy and Conclusions ....................................... 73

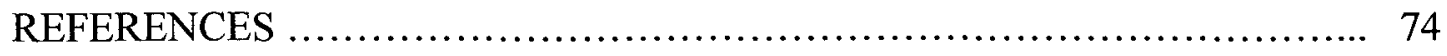




\section{LIST OF TABLES}

Table $1 \quad$ Survey Dimensions and Variable Category .................... 45

Table 2 Summary of Demographic and Study Variable Characteristics .... 51

Table 3 Summary of Military Deployment Experience of Fatigue ......... 52

Table $4 \quad$ Frequencies for Fatigue Avoidance Strategies ................ 55

Table 5 Frequencies for Fatigue Countermeasures ..................... 56

Table 6 Cross Tabulation for Fatigue Experience and Predictor Variables 60

Table $7 \quad$ Regression Coefficients ................................... 62 


\section{LIST OF FIGURES}

Page

Figure 1 Theory of Unpleasant Symptoms: An Update ................... 9

Figure 2 Experience of Fatigue During Call ........................... 58 


\section{LIST OF APPENDICES}

Appendix A Theory of Unpleasant Symptoms: An Update .................... 85

Appendix B Institutional Review Board Approval from USD ................ 86

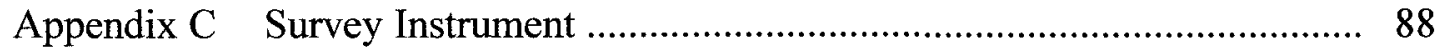

Appendix D Cover Letter ....................................... 94 


\section{CHAPTER 1 \\ INTRODUCTION}

It has been a decade since the Agency for Healthcare Research and Quality (AHRQ) released their seminal report 'Making Healthcare Safer', urging healthcare organizations to examine and improve patient safety outcomes (Kohn, Corrigan, \& Donaldson, eds., 2000; Shojania, Duncan, McDonald, Wachter, \& Markowitz, 2001). Nevertheless, adverse events continue to be common and the reduction in medical errors remains a healthcare priority.

Researchers were encouraged to investigate how human factors, such as healthcare worker fatigue, contributes to medical error (Shojania et al., 2001). Based upon limited empirical evidence of healthcare professionals who report medical error is related to their fatigue, numerous federal, state, institutions, accrediting bodies, and safety organizations forced changes for patient protection; specifically the influence of fatigue related to shift length and the way medical error is reported. These changes shift blame away from a person and dissects a process for improvement.

\section{Work Hour Restriction, Mandatory Overtime, and Medical Error}

In 2003, work hour restrictions were set for medical residents and interns (Accreditation Council for Graduate Medical Education, 2007; 2011). In 2007, there was 
a near doubling of states with mandatory adverse event reporting requirements and the Joint Commission implemented unannounced visits to enforce a variety of patient safety goals (Wachter, 2009). Finally, by 2008, 13 states enacted state and federal mandates restricting mandatory overtime for nurses (The American Nurses Association Website, 2008). While mandatory overtime and trainee work hours were adjusted, there were no work hour restrictions set for staff workers (non-student or resident status), such as shift length or number of calls per week. Notably, certified registered nurse anesthetists (CRNAs) and advanced practice nurses, who are scheduled for call (whether a requirement of their position or voluntary), do not have federal work hour restrictions despite anesthesia being labeled a 'safety-sensitive' profession; nor is there a recommendation from the Institute of Medicine (IOM). The IOM does recommend a safe shift length for staff nurses as 12 consecutive hours and there are multiple state provisions; for example in Oregon, a nurse cannot work two hours beyond a regularly scheduled shift (Institute of Medicine, 2004).

\section{Fatigue and Medical Error}

Fatigue is a common symptom of normal physiologic and psychologic response to exertion or stress. Stedman's Medical Dictionary (2005) defines fatigue as a state, after a period of mental or physical activity, of lessened capacity or motivation for work or efficiency, usually accompanied by weariness, irritability, and sleepiness. Fatigue is difficult to describe partly because it is a complex, multidimensional, subjective phenomena without biological markers. Indeed, the need of a standardized measure was identified in the National Institutes of Health (NIH) Roadmap for Research initiatives 
(Fitzpatrick \& Wallace, 2006). In the study presented here, fatigue is defined as 'a feeling of mental or physical exhaustion, beyond being tired, as a result of continued stimulation'.

There is increasing empirical evidence on the effects of fatigue from extended shift lengths and its relationship to patient care error and healthcare worker injury. Nurses working longer than 12 hours encounter decreased vigilance on the job, a nearly two-fold chance of making a patient care error, and have a significantly increased risk of a needle stick injury (Scott, Hwang, \& Rogers, 2006; Trinkoff, Le, Geiger-Brown, \& Lipscomb, 2007). It was discovered that nearly a quarter of New Zealand anesthesiologists who filed an incident report indicating fatigue was a factor, received 2 hours of sleep less than their baseline during call the previous night $(\mathrm{N}=389)$ (Gander, Millar, Webster, \& Merry, 2008). Finally, medical interns working a traditional schedule of five 24 -hour shifts a month, versus more frequent 16 -hour shifts, made $36 \%$ more serious medical errors and experienced 61\% more needle sticks (Landrigan et al., 2004; Ayas et al., 2006). The connection between fatigue and medical error is confounded by human influences of an individual's response to sleep loss (Van Dongen, Baynard, Maislin, \& Dinges, 2004), medical competence, and institutional processes which may contribute to medical error.

\section{Patient Safety Terms and Definitions}

There is some disagreement in the definition of terms used to define patient safety. The study proposed here will use the Agency for Healthcare Research and Quality (AHRQ) and Institute of Medicine (IOM) definitions when seeking to capture 
self-reported medical errors. As the patient safety movement evolves, definitions may become universally acceptable.

\section{Vigilance and Anesthesia}

Anesthesia is considered a 'safety-sensitive' occupation, along with firefighters, nuclear power plant workers, aviators, those in the military, and other high-risk professions in which optimal functioning is critical at all times. Hospital personnel working a call-shift, or call, are to perform duties in an on-demand schedule for a predetermined shift length. Typical health institution call shifts start "after hours", are 15-16 hours during the weekday and 24 hours during the weekend or holidays. Certified Registered Nurse Anesthetist's work these call shifts and are to remain vigilant while administering anesthesia in the operating room or performing procedures such as a labor epidural.

Intra-operative emergencies are inherent in anesthesia and CRNAs handle potentially life-threatening situations making vigilance mandatory. The American Association of Nurse Anesthetist's (AANA) statement of their scope and practice lists its fifth standard as the responsibility to monitor the patient's physiologic condition and clarifies that "continuous clinical observation and vigilance are the basis to safe care" (Jordan, Kremer, Crawforth, \& Shott, 2001). Jordan et al (2001) provided the only review of the CRNA closed claims database of CRNA cases from 1989 to 1997 and found vigilance was lacking in 121 of 151 claims $(80 \%)$. They noted although vigilance is hard to define, safe care requires continuous clinical observation. The review found that in $62 \%$ of the cases, the CRNA could have taken corrective action to prevent an 
adverse event. Unfortunately, fatigue was not isolated as a contributing factor to the CRNA's lack of vigilance. In contrast, in a study that suggested vigilance might not be affected during anesthesia duties, Kabes and colleagues (2010) observed performance of registered nurse anesthetist students (SRNAs) using psychomotor vigilance reaction times. Their findings suggest long work hours may not result in fatigue that affects performance. Although SRNAs typically work longer than 50 hours a week including call, reaction time of SRNAs, in this study, did not decrease from the start to the end of a shift or over a 7-day workweek.

\section{Circadian Rhythm, Neurobehavioral Performance and Neuromodulation}

Sleep involves complex neuronal networks, expressed by altered physiologic functions of heart rate, blood pressure, hormone secretion, and gastrointestinal function (Rowland \& Pedley, 2010). Three parameters used to measure sleep involve electroencephalogram (EEG) activation, electrooculography (EOG), eye movement activity, and muscle tone (evaluated by the electromyography [EMG]) (Rowland \& Pedley, 2010). Sleep is defined by recurring cyclic episodes of rapid eye movement (REM) sleep and non-REM sleep (which include two stages of slow wave sleep [SWS] and two lighter stages of sleep) (Diekelmann \& Born, 2010). Neural wave and neuromodulator activity are most pronounced during SWS and REM (Diekelmann \& Born, 2010). During SWS (called 'early sleep'), acetylcholine (ACh) and cortisol levels decrease while noradrenalin (NAd) and serotonin levels remain the same; during REM sleep ('late sleep'), ACh and cortisol increases while NAd and serotonin levels increase (Diekelmann and Born, 2010), there is also a loss of thermoregulation (Rowland \& 
Pedley, 2010). Melatonin is a hormone (derived from serotonin), believed to have a powerful effect on the circadian rhythm and sleep behavior (Kayumov, Zhdanova, \& Shapiro, 2000).

A circadian pacemaker, located in the suprachiasmic nuclei in the hypothalamus, controls an endogenous sleep-wake pattern in humans (Barger, Lockley, Rajaratnam, \& Landrigan, 2009). Sensitive to bright light, this circadian rhythm controls nearly all physiologic and behavioral variables promoting alertness and elevated performance during the day and decreased alertness and performance at night (Barger et al., 2009).

Ruger and colleagues (2006) summarized the literature and found that nighttime bright light exposure reduced sleepiness and increased alertness while suppressing melatonin and increasing core body temperature and heart rate. Sleep onset is reportedly enhanced by a decrease in core and peripheral skin temperature and increase in endogenous melatonin (Markwald et al., 2010).

Night-shift workers function against two physiological processes: the natural circadian rhythm and sleep pressure, which is brain wave activity, which builds during wakefulness (Taillard, Philip, Coste, Sagaspe, \& Bioulac, 2003). Both processes increase sleepiness at night and decrease neurobehavioral performance (Taillard, Moore, Claustrat, Coste, Bioulac, \& Philip, 2006), particularly after sleep deprivation (Van Dongen \& Dinges, 2005). Extended wakefulness is associated with an increase in subjective sleepiness, decrease in neurobehavioral performance, and decreased alertness (Philip et al., 2006). 
Achieving less sleep per night than a person's optimal sleep time contributes to accumulating a 'sleep debt'. A sleep debt can manifest in a range of neurobehavioral decreases in attention and cognitive performance (Banks \& Dinges, 2007), executive attention, vigilance, and working memory (Goel, Rao, Durmer, \& Dinges, 2009). Neurobehavioral deficits accumulate with days of partial sleep loss to levels equivalent to 1 to 3 nights of total sleep loss (continued wakefulness) (Banks \& Dinges, 2007). Alarmingly, with increasing sleep deprivation, cognitive deficiencies can accumulate without recognition by the affected individual (Goel et al., 2009).

\section{Countermeasures}

A fatigue countermeasure is the accepted terminology in fatigue literature to describe practices to counteract fatigue. The AHRQ and American Academy of Sleep Medicine endorse naps during long work shifts to combat fatigue (Guilleminault \& Ramar, 2006), although there are only a few field studies to determine the efficacy of this strategy. Hayashi, Masuda, and Hori (2003) found improved performance in decreasing afternoon sleepiness, with a short nap combined with caffeine, or a nap combined with light exposure, as more effective than a nap with face-washing. Nightshift workers demonstrated maintenance of two tests of alertness by using a combination of a nap and caffeine, versus just napping (Schweitzer, Randazzo, Stone, Erman, \& Walsh, 2006). Dr. Mark Rosekind (2005), a long-time clinically oriented fatigue researcher, presented a summary of evidence aiming to improve patient safety by reducing healthcare worker fatigue. He made the following recommendations: a) incorporate effective evidencesupported fatigue strategies (timing of naps and caffeine); b) establish policies regarding 
consecutive calls and minimum time off; and c) provide scientific support of alertness programs. Scott et al. (2010a) reviewed the literature for programs that would mitigate fatigue in safety-sensitive industries and found: a) education about shift length, b) scheduling, c) changes in work place design, and d) fatigue countermeasure programs. However, in their systematic evaluation, efficacy was limited and there is no applicability to the healthcare setting. Fatigue studies of medical personnel measure the effect of shift length on performance, usually without an introduction of a fatigue countermeasure; those that use a countermeasure use a single intervention, usually a nap. Primarily, there is a need to determine if CRNAs experience fatigue on call and if they do, identify fatigue interventions.

\section{Conceptual Model}

The middle-range theory of unpleasant symptoms, (Lenz, Pugh, Milligan, Gift, \& Suppe, 1997) (Figure 1) is a conceptual pathway for the conflict of physiologic, psychological, and situational factors, which can influence a person's health and affect their performance. In the case of anesthesia performance and fatigue: a) the physiologic factor of the circadian rhythm; b) psychological factors, such as stress from the number of hours awake and perception of fatigue; and c) situational factors, such as workload or professional obligations; all could contribute to development of unpleasant health symptoms (i.e. pain, headache) and affect performance. 
Figure 1

Theory of Unpleasant Symptoms: An update

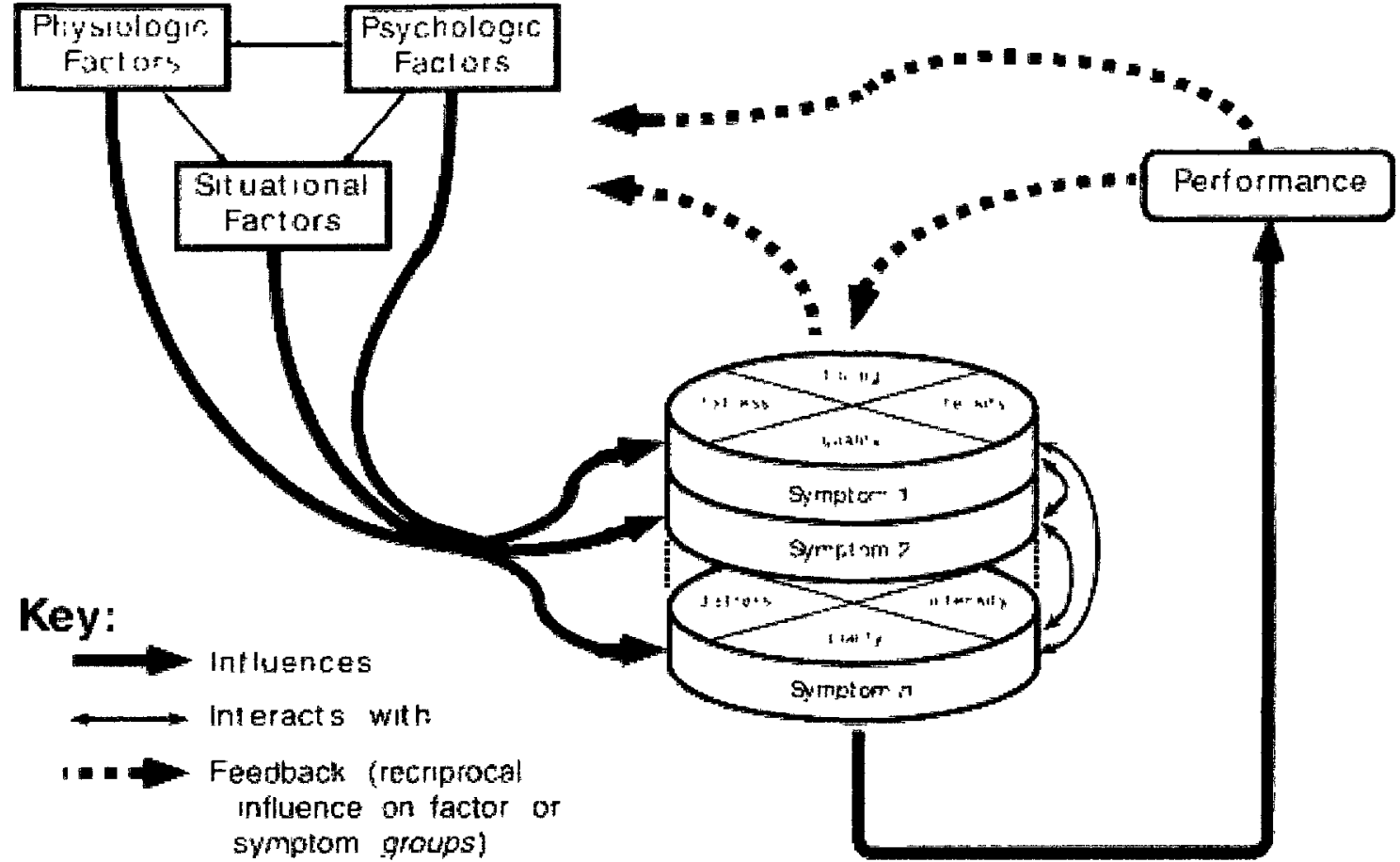

${ }^{1}$ From: The middle-range theory of unpleasant symptoms: An update, by Lenz, E. R.; Pugh, L. C., Milligan, R. A.; Gift, A., \& Suppe, F. (1997). Advances in Nursing Science 19(3), p.16. Reprinted with permission / Copyright (C) 2009 Wolters Kluwer 


\section{Purpose and Research Aims}

The purpose of this study was to examine whether Certified Registered Nurse Anesthetists experience fatigue during call and to assess their use of fatigue avoidance strategies (practices that prevent fatigue) and fatigue countermeasures (practices that decrease fatigue) to mitigate its effects. The study aims are:

Aim 1. To characterize fatigue experience by duration of call, use of fatigue avoidance strategies to prevent fatigue prior to call, and use of fatigue countermeasures during call, among a national sample of CRNAs.

Aim 2. To examine the relationships between fatigue experience, duration of call (weekday or weekend), call days per month, anesthesia days per week, occurrence of physiological or psychological symptoms, use of fatigue avoidance strategies, fatigue countermeasures, and selected demographics among a national sample of CRNAs.

Aim 3. To explore factors related to the odds of experiencing fatigue during call.

\section{Importance to the Advancement of Nursing Science}

The scientific understanding of fatigues physiological and behavioral processes that influence the healthcare shift worker is a decade old, albeit the research link between fatigue and patient error are nascent. Recommendations of fatigue countermeasures in high-risk industries have not yet been widely accepted in healthcare. Coexisting reasons are non-support and lack of knowledge by healthcare administration, lack of individual awareness of fatigue's effect on performance, and lack of a causal relationship between healthcare worker fatigue and patient error. Knowledge gained from this study has the 
potential to identify if fatigue is a concern in the nurse anesthetist population and to examine current CRNA fatigue interventions.

Nurses make up the largest professional body in the healthcare community (Bureau of Labor Statistics, 2008) and as such, can influence development of healthcare policies, patient safety initiatives, and advocate for maximum safe working limits. Personal responsibilities in fatigue prevention are desirable but the conflict between physiological demands, psychological influences, and work demands require alternatives for individuals in safety-sensitive occupations.

Current evidence is lacking as to whether CRNAs working call shifts greater than 12 hours are fatigued. Determining if there is a relationship between sleep duration, shift length, and fatigue measures in staff nurse anesthetists would provide some guidance to the next step of whether fatigue and medical error are related. Fatigue's impact on the healthcare worker is wide spread; findings from this study may benefit other healthcare workers, as well CRNAs. 


\section{CHAPTER 2}

\section{REVIEW OF THE LITERATURE}

The purpose of this study is to examine whether CRNAs experience fatigue during call and to assess their use of fatigue avoidance strategies (practices that prevent fatigue) and fatigue countermeasures (practices that decrease fatigue) to mitigate its effect. In this chapter, the literature review is presented to include studies of fatigue, measurement issues, physiologic, psychological, and situational factors of fatigue, and the impact on the healthcare worker. The conceptual framework for the study is also included.

\section{Fatigue}

In addition to the medical definition of fatigue, as a state of decreased motivation for work or efficiency accompanied by sleepiness, fatigue may arise unexpectedly and from any cause when energy expenditure exceeds a person's capability. Dr. Barbara Piper, a preeminent authority in the study of fatigue, made distinctions of acute and chronic fatigue over 20 years ago, which are still accepted today. Piper and colleagues (1989) characterizes acute fatigue, as occurring over a short period, is protective for the individual, is experienced in healthy persons, and is relieved by rest. In contrast, chronic fatigue does not have a known purpose, can have multiple causes, is frequently related to 
an illness (not exertion or sleep deprivation), persists over time, and may not be relieved by rest. Chronic fatigue is typically more problematic when pathologic conditions arise from constant fatigue; however, even acute fatigue can become problematic if situational demands require cognitive and complex psychomotor skills. A subcategory of chronic fatigue is partial chronic sleep deprivation, which occurs when an individual receives less sleep per night than their optimal time and accumulates a 'sleep debt'. Over time, a sleep debt can manifest in declines in attention and cognitive performance, (Banks \& Dinges, 2007); unlike chronic fatigue, it is typically relieved by sleep. Inter-individual responses for how a person will respond to a sleep debt vary significantly, however, over time a person's optimal functioning is affected (Van Dongen, Baynard, Maislin, \& Dinges, 2004).

\section{Measurements}

Lan, Ji, and Looney (2002), reviewed instruments to measure fatigue to include physiologic, behavioral, performance observations, and self-report. They concluded a novel approach was necessary to directly measure fatigue. They designed a model that integrates evidence from a multitude of sources (sensory data and contextual information [i.e. work environment, sleep quality, etc.]), to demonstrate they could predict and model fatigue. Later, Ji, Lan, and Looney (2006) furthered their work by designing a fatigue monitor supporting validity of the proposed fatigue model. There is still no consensus on the model.

Physiologic Measurements. Several of the most accurate tests of objective fatigue measures are obtained from electroencephalogram recordings (used to determine 
brainwave activity and as reference for other physiologic sleep measures) (Lan et al., 2002): the Multiple Sleep Latency Test (MSLT) (Carskadon et al., 1986), and the Maintenance of Wakefulness Test (MWT) (Littner et al., 2005). The MSLT is considered the 'de facto' standard according to the American Academy of Sleep Medicine's last delivered Practice Committee guidelines (Littner et al., 2005). The MSLT is a measure of a person's brain wave, EEG, muscle activity, and eye movements (Carskadon et al., 1986). The second most commonly used objective test is the MWT, which measures the ability of a subject to stay awake for a defined time (Littner et al., 2005). A drawback of these measures is the limited application in wide-range studies because of their intrusiveness and time commitment for proper administration.

Behavioral Measurements. An actigraph is a wristwatch-like device which measures body movements over a specified time. As a behavioral measure, it provides accurate and objective data found to correlate with measures of the EEG. Visual measures such as eyelid closure, gaze, and head nod use computer systems to extrapolate data of a person's attention and possibly vigilance (Lan et al., 2002). Both measures are relatively expensive and the visual measure is intrusive.

Performance Observation Measurements. Performance measures range from simple to complex, assess reaction times to visual or auditory stimuli, and are constructed of psychomotor or vigilance tests. One example is the psychomotor visual response task (PVT) which records the time it takes an individual to observe a visual stimulus and press a button. The PVT is a correlational measure between increased lapses of performance and decreased alertness (Doran, Van Dongen, \& Dinges, 2001) and is a widely accepted 
measurement in fatigue studies. Disadvantages of the tests are that some need expert analysis and some are not self-administered.

Self-Report Measurements. Most common are indirect measures of performance and fatigue that include subjective self-report via diaries or instruments such as the Epworth Sleepiness Scale (Johns, 1991) and the Visual Analog Scale for Fatigue (Lee, Hicks, \& Nino-Murcia, 1991). These measures are based on recall and do not measure real-time fatigue, although they are feasible and easy to administer.

\section{Fatigue Influences}

Some of the difficulties in fatigue measurement is that typically, the instrument is only designed for the population tested (i.e. post-partum or cancer patients), and may only focus on emotional and cognitive expression, for example trying to quantify fatigue effect on energy expenditure (Tiesinga, Dassen, \& Halfens, 1996). In this study, fatigue is defined as 'a feeling of mental or physical exhaustion, beyond being tired as a result of continued stimulation'.

Fatigue results from complex multi-factored influences that, after 30 years of research, is still not well-understood (Lan et al., 2002). To aid in understanding physiology (i.e., circadian rhythm, time asleep, etc.), psychology, (i.e., the individuals response to fatigue), and situational influences of fatigue, the middle-range theory of unpleasant symptoms (Lenz et al., 1997) is introduced.

Physiologic Factors. In humans, there is a physiologic need for sleep. Sleep loss, no matter what the cause, has a variety of negative health consequences. Influences of 
sleep, such as the circadian pacemaker, melatonin influences, amount and duration of sleep was presented in the previous chapter.

Barger, Lockley, Rajaratnam, and Landrigan (2009) condensed the findings of four separate studies to conclude that, in healthy persons, there are four physiologic determinants of alertness and performance. The first is the circadian phase, which is sensitive to the time of day. A visual psychomotor performance task was administered over a 32-hour vigil $(\mathrm{N}=10)$, showing poorest performance toward the end of the biological night (midnight) with improvement around 0400 with a 'drive for alertness'. Second, a simple addition test was administered to 94 subjects and it was discovered that with increased time awake, cognition declined. The third study included a measure of performance in partial chronic sleep loss at night. Participants were restricted to 4, 6, or 8 hours per night over a two-week period; daily lapses in attention were measured. Performance deteriorated for the 6-hour sleep group as if they had been continuously awake for 24 hours and in the 4-hour group, as if kept awake for 72 straight hours. Sleep inertia (decreased motor dexterity and grogginess) was shown to affect performance, especially if awaken abruptly. To identify effects of sleep inertia, cognitive throughput was measured for 4 hours over three days after a normal 8-hour sleep. Subjects showed maximal performance 2 hours after awakening and probability of a 'high risk of a fatigue-related error within 30 minutes of awakening'. The authors contend that each factor is independently associated with a decrease in neurobehavioral performance and an increased risk of accidents, suggesting workers in circadian rhythm desynchrony are at risk for significant health care problems including obesity, gastric ulcers, and 
cardiovascular disease. This review highlights the intertwined effects of performance and alertness in healthcare shift workers and those in an after-hours call status with disruption of the circadian phase.

Psychological Factors. Baranski (2007) attempted to determine whether study participants were able to predict when they were fatigued. 'Metacognition' or the ability to self-monitor cognitive performance, has received little attention in relation to sleep deprivation. Baranski explains the prefrontal cortex, responsible for 'executive functioning' is susceptible to sleep deprivation; as is primary cognitive task performance (i.e., simple vigilance tests, psychomotor tasks, etc.). Baranski predicted people might be able to predict sleep deprivation effects on metacognitive functioning, more so than simple primary cognitive tasks because of the need for higher level executive functioning, such as decision-making and problem solving. During 28-hours of sleep deprivation, 64 adults were monitored for cognitive work and metacognitive judgment. In all tasks participants accurately assessed cognitive performance impairment when deprived one night of sleep (complex team-decision making, individual short tasks, and questions of mood, fatigue, and workload).

In a recent study, West et al. (2009) attempted to isolate the phenomena of resident distress, as opposed to fatigue, as a contributor to a self-perceived major medical error. Residents entering the Mayo Clinic program from 2003 - 2009 were surveyed every three months through their residences. Participants completed a survey asking if they were concerned about having made a medical error in the past three months, a lineal fatigue $\log$, and a standard measurement tool addressing the quality of life, a burnout 
scale, depression symptoms, and a sleepiness scale (introduced in 2007). Residents who reported at least one error had significantly lower quality of life scores (difference -0.41 ; $p=.02$ ) and higher burnout levels; nearly $70 \%$ of these residents also had a positive depression score at least once in their residency. Residents who reported an error also had a greater fatigue score (difference, $0.54 ; p=.006$ ). A one-point increase in fatigue or the sleepiness scale increased odds of making an error at least $10 \%$. Study findings indicate fatigue and distress are distinct and each contributes to medical error to an extent that is concerning in patient safety.

Intensive care unit (ICU) house staff (resident physicians and fellows), at a single institution, were observed for the effect of the resident-mandated work-hour reductions on their quality of life (Parthasarathy, Hettiger, Budhiraja, \& Sullivan, 2007). Secondary objectives were subjective and objective measures of sleep time and sleepiness, selfreport of sleepiness while driving, and intercepted errors in written orders. The workhour reduction resulted in a decreased schedule from a 34 to 30 -hour continuous workday (once every four days). After the work hour reduction, internal medicine residents $(n=$ 34) showed a decrease in work hours but critical care fellows $(n=10)$, did not. Residents, but not fellows, showed a significant improvement in sleep time $(p=.04)$, although neither subjective nor objective sleepiness measures improved in either group. Quality of life scores improved in only three of eight domains for residents (vitality, social functioning and mental health scores), without improvement for fellows. The work-hour reduction was shown to be independently associated with a decrease in written order entry errors $(p=.03)$ and resident sleepiness while driving decreased from 21 residents to 
11. Multiple measures in this study did not change significantly over the course of the study (i.e., quality of life and sleep latency). Interestingly, although objective and subjective sleep measures did not improve, intercepted errors and sleepiness while driving improved, benefiting the patient and healthcare worker.

Berlin (2007) reviewed court cases where employers were sued for negligence in allowing sleep-deprived workers to drive after being relieved from their duties. The only healthcare case was in Chicago when a first-year medicine resident fell asleep driving home after a 36-hour work shift, causing a car crash permanently disabling the other driver. The plaintiff filed a medical malpractice suit alleging a breach of duty by the medical center's administrators, charging they should have known excess work hours could result in sleep deprivation that can impair judgment. The trial court dismissed the lawsuit, and upon appeal, the Appellate Court ruled the medical center was not liable. This is in contrast to the Appeals Courts in two other states, which ruled in favor of judgment against an employer, when they 'allow' a physically or mentally impaired employee to drive home after extended work hour conditions that result in third-party injuries. Fatigue effects on these driver's judgment and psychomotor and performance skills were seemingly not known to them.

To capture the prevalence of drowsy driving in nurses, data were collected over a four-week period from 895 full-time hospital staff nurses (Scott et al., 2007). Nearly 600 nurses reported at least one episode of "drowsy driving" over the course of the study; once every four shifts. Nurses who worked longer than 12.5 hours doubled the risk of drowsy driving. Nearly $16 \%(141 / 895)$ of nurses reported at least one motor vehicle 
crash (MVC) or near crash (near-MVC), and 57 nurses reported two or more MVC/nearMVC. This is consistent with a 2002 survey of over 4000 drivers by the National Highway Traffic Safety Administration (2003) that found 37\% of drivers reported having fallen asleep or nodded off while driving at least once in their lives, including $11 \%$ within the past year. The large sample size and reliable data collection technique seems to reflect a well-designed study, however the sample did not include administrators and advanced practice nurses.

Only one study of physiologic sleep markers was located for review. Ekstedt, Akerstedt, and Soderstrom (2004) investigated the relationship between the number of polysomnography (PSG) arousals at night and stress factors measured by physiologic measures: blood and salivary cortisol, cholesterol, blood pressure, and heart rate. Diaries of 24 Swedish information technology employees were analyzed for sleep times, stress, work hours, and mood. None of the workers were diagnosed with a new disease (i.e. cardiovascular, diabetes, etc.), in the past 12 months. The number of arousals per night was correlated with the amount of work stress and if workers brought work home (had unclear boundaries between work and leisure time); it was a significant predictor of increases in all of the measured physiologic markers.

Situational Factors - Performance and Shift Length. Surgeon and obstetrician work hours, sleep opportunity, and rates of surgical complications in post nighttime procedures were collected from chart reviews from $1999-2008$ (Rothschild et al., 2009). Surgeons $(n=86)$ and obstetricians $(n=134)$ who performed a procedure during the preceding night (12am to 6am) were included. Sleep opportunity was calculated from the 
end of the overnight procedure to the first procedure the next day. A control procedure was designated as the same procedure, by the same surgeon, on days not preceding an overnight procedure. Of 919 surgical procedures compared with 3552 surgical control procedures, and 957 obstetric procedures compared with 3945 obstetric control procedures, the complication rate for post nighttime procedures and control procedures was $5.4 \%$ and $4.9 \%$ respectively. Surgeons with less than 6-hour sleep opportunity had a post-nighttime complication rate of $6.2 \%$, compared with surgeons who had more than 6hour sleep opportunity with a surgical complication rate of $3.4 \%$. There were no significant differences in post-nighttime procedures for preventable complications compared to control. Surgeon complication rate for post nighttime procedures beyond a 12-hour work duration yielded no significant difference when compared to surgeons working less than 12 hours. This unique study, comparing staff surgeon's rate of complications to sleep opportunity, explores the phenomenon that a single night of sleep disruption could contribute to a higher rate of surgical (not obstetric) complications the following day. Circadian rhythm influences of a nighttime surgical procedure and undocumented chronic sleep deprivation may have been influencing factors. The authors admit, there is limited supportive or refutative evidence that experienced physicians cope better than residents regarding a single night of sleep deprivation, or that medical setting findings can be extrapolated to the often-interactive environment of the operating room or labor ward.

Ayas et al. (2006) reported an increase in percutaneous injuries (needle stick) when interns worked an extended work duration (greater than 12 hours and at a usual 
mean of the $20^{\text {th }}$ hour of consecutive work), versus less than 12 hours. Diary logs of 192 interns were analyzed for the 28-day study. In the extended work duration group, there were 1.31 opportunities per/1000 for a needle stick versus $.76 / 1000$ opportunity in the non-extended work group (odds ratio, $1.61 ; 95 \%$ confidence interval, 1.46-1.78). The two most reported contributing factors of the injury were lapse in concentration and fatigue ( $64 \%$ and $31 \%$, respectively).

Scott, Rogers, Hwang, and Zhang (2006) collected data from 502 critical care nurses to examine scheduled shift length versus actual shift length. Of $44 \%$ of the work shifts scheduled for 12 hours, $67 \%$ exceeded that and nearly $11 \%$ worked longer than 16 hours at least once during the 28-day study. Twenty seven percent of nurses self-reported at least one error and $38 \%$ one near error during the study period. The majority of the errors $(57 \%)$ and near errors $(28 \%)$ involved medication administration. Error and near error rates were associated with longer shift duration and decreased vigilance. The risk for making an error nearly doubled when nurses worked longer than 12.5 consecutive hours (odds ratio $1.94, p=.03$ ).

Scott, Hwang, and Rogers (2006) explored stress and fatigue among nearly 400 hospital staff nurses providing care to elders versus children living at home. Sleep duration and work performance effects by caregiver status were examined over 4 weeks by logbook data collection. Nurses caring for family members reported more episodes of work sleepiness, more physical and mental fatigue, and reported higher levels of stress, than those without care dependents; sleep duration between groups was not significantly different. Nurses providing elder care were two times as likely to commit a medication 
error than those caring for children less than 18 years old (odds ratio 2.38). As the population ages and informal care grows in the home, attention to the number of work hours dual care providers' work should be scrutinized.

Trinkoff et al. (2007) examined the association between working conditions and needle stick injury in a probability sample of 2,624 licensed registered nurses from two states. A 3-wave longitudinal survey was conducted between November 2002 and April 2004. The impact of psychological demands (i.e. working hard, very fast, long periods of concentration, etc.), physical demands (i.e. heavy lifting, etc.), and the association between work schedule and frequency of needle stick injury were examined. Using regression of an individual's work-schedule with age adjustment revealed that work schedule variables (hours worked per day, weekends per month, non-day shift, and shifts greater than 13-hours), were significantly associated with occurrence of needle stick injuries in the past year.

\section{Vigilance and Anesthesia}

The CRNA Closed Claims Database was reviewed from 1989 - 1997 (Jordan, Kremer, Crawforth, \& Shott, 2001). Reviewers found 121 of 151 CRNA claims where vigilance was lacking; defined as being watchful to detect patient harm. In $62 \%$ of those cases, the reviewers determined the CRNA could have taken corrective action to prevent an adverse event. Unfortunately, fatigue was not isolated as a factor in the lack of vigilance in the CRNA cases (i.e. distraction, not fatigue, may have contributed to the adverse event). 
Although dated, an important finding in a study conducted by Owens (2001) suggests neurobehavioral processes, (mood, affect, and learning), may have an influence on medical error when medical trainees experience fatigue. The researcher reported trainees with newly learned tasks that required sustained vigilance or an increased duration were more vulnerable to acute sleep loss, and that accuracy in performing that task, may be sacrificed for efficiency. Although this study used trainees, the application that any healthcare worker who performs tasks which are new or requires sustained vigilance or duration, for example a long anesthetic case, could be similarly affected. In contrast, in a recent field dissertation study, Kabes, Knop, and Wosje (2010) suggest registered nurse anesthetist student's (SRNAs) vigilance may not be affected by fatigue. Vigilance was measured by psychomotor vigilance reaction times (PVT) in 11 SRNAs . Response time (time of visual recognition of a stimuli and push of a button) did not decrease, as hypothesized, over the course of a 7-day workweek, or from the start to the end of the shift. A convenience sample of 13 SRNAs completed activity logs, wore actigraphs, and performed PVTs at the beginning and end of each shift over eight days. The average workweek was reported as 50 hours. Shift start and end times were not offered except that the start day was Saturday and it was deduced that only one subject worked one call shift. Average sleep time per participant was 7.7 hours (median 7.5 hours) with an average minimum total sleep of 4.1 hours for one subject over 3 days. Sleep times per subject over the week revealed a minimum average sleep time of 6.7 hours. Using the PVT, average mean reaction times (RT) from the beginning to the end of the shift were examined. Average mean RT before the shift was 331 milliseconds 
(median 323) with a range of 159 milliseconds; the average mean RT at the end of the shift was 348 milliseconds (median 322 milliseconds). Even though the data show all subjects' average mean RT increased from the beginning to the end of the shift by 17 milliseconds, individual performance over the week showed five subjects' mean end of shift RTs decreased while five increased. Data for the PVT was measured for days the subject worked ( 5 days in this study); the group RT average from the start to the end of the week fluctuated from 354 milliseconds to 334 milliseconds, respectively, which does not support a decrease in vigilance. Unfortunately, only one call shift was captured in this study, which the authors admit could have been a primary factor in onset of chronic partial sleep loss ultimately affecting vigilance and their results. Arguably, there is a difference in the PVT used to measure vigilance and the sometimes-complex cognitive decision-making steps necessary to respond to an anesthetic event, but this study provides a first step in studying fatigue effects in anesthesia personnel.

\section{Performance During Acute Fatigue - Simulation Environments and Field Studies}

Across a two-week work cycle, the work patterns for nearly $400 \mathrm{New}$ Zealand anesthesia trainees and staff were monitored using sleep and performance measures (Gander et al., 2008). Sleep was measured by actigraphy and performance was measured by a PVT, pre and post 24-hour duty. Trainees worked either a 24-hour shift, 9-hour dayshift, or occasionally a 10 -hour nightshift. On $11 \%$ of dayshifts and $23 \%$ of nightshifts, trainees worked with greater than 2-hours of acute sleep loss. Trainees performance post night shift revealed the slowest $10 \%$ of reaction times $(p<.01)$. Staff worked clinical days and occasionally, covered after-hours services by being available on 
call. At the end of two weeks, trainees showed poorer performance with increased shift length, longer time since awakening, greater acute sleep loss and more total work in the past 24 hours. On $8 \%$ of dayshifts and $14 \%$ of day plus call, staff worked with greater than 2-hours of acute sleep loss. Worth mentioning is that $23 \%$ of staff anesthesiologists who filed an incident report indicating fatigue was a factor, reported greater than 2 hours less sleep than their baseline the call-night prior. Although clinical performance measures were not included, potentially negative consequences for those patients whose anesthesiologist filed an incident report implicating fatigue as a factor, is concerning.

Two separate but concurrent studies provided a foundation for the IOM to issue a statement for even stricter work-hours for residents in 2006. Landrigan and colleagues (2004) examined the work hours of medical interns working in the ICU who performed traditional 24-hour call every third night to a nontraditional 16-hour shift group. The intervention group received nearly 20 hours less work per week and 6 hours more sleep (Lockley et al., 2004). Interns working the traditional schedule had $36 \%$ more serious medical errors and nearly 6 times more serious diagnostic errors than the intervention group. Ironically, there were no differences between groups in reports of adverse event during the nearly 2000 days of data collection, suggesting a multicollaborative and corrective effort of other healthcare providers (presumably nurses, pharmacists, and hospitalists), who understand they work with fatigued residents.

Many of the studies mentioned include participants experiencing chronic partial sleep loss (an individual receiving less than optimal sleep time for days or weeks), compounded by acute sleep loss (continued wakefulness for short periods [ $<48$ hours]). 
Participants in the studies may not be too different from the general population, according to a poll conducted by the National Sleep Foundation (2008), revealed 1000 adults admitted they slept approximately 6 hours and 40 minutes on weekdays yet reported needing 7 hours and 18 minutes to function optimally.

There is currently a growing scientific base supporting fatigue's effects on the shift nurse and the safety of patients (Rogers et al., 2004; Scott, Hwang, \& Rogers, 2006; Trinkoff et al., 2007; Scott et al., 2010b). These studies recognized the nature of call shift of advanced practice nurses were different and excluded them from the study or, simply did not include the population. This study will attempt to add to the gap in the literature.

\section{Simulation Studies}

Simulated clinical cases provide a realistic and safe environment to study healthcare worker fatigue and the use of fatigue countermeasures. Simulation provides predictable clinical experiences and can replicate patient encounters in a safe learning environment. In the past 6 years, simulation has exploded into healthcare training (Gaba, 2007), and has been incorporated into nearly every curriculum (nurses, residents, and allied health professionals). The ultimate goal for using simulation is to improve patient safety and healthcare (Cannon-Diehl, 2009; Gaba, 2007). Simulated clinical cases can closely replicate patient encounters providing a realistic and safe environment to study the performance of fatigued healthcare workers.

Howard et al. (2003) used a simulation environment to study the effects of sleep deprivation on five performance measures in 12 anesthesia residents. One group was 
allowed an extended period of sleep and other endured 25 hours of continued wakefulness, prior to a 4-hour simulated anesthesia case. Measures included reaction times (measured by PVT), tasks to complete a check of the anesthesia machine, clinical management of patient conditions, and three vigilance probes. Even though the sleep deprived group reported more sleepiness, clinical skills and vigilance was not statistically significant between groups. Subjects in both groups made clinically relevant errors but a relationship to sleep deprivation was not found. This suggests psychomotor and cognitive testing in the complex arena of the clinical environment is difficult to assess. A limitation of the study was to document competency of the individuals prior to the study.

Surgery residents are the most-studied group of healthcare personnel using simulation to measure performance during call. The following studies involve short-term sleep deprivation (a single night of call or one week of night shift).

Grantcharov and associates (2001) used a pretest/posttest design, to measure the performance of surgery residents $(\mathrm{N}=14)$ for six laparoscopic skills; once during normal working hours and once after a night call when the residents slept less than 3 hours. Scores were analyzed for error of motion, time of motion, and economy of motion. After a night call, posttest scores revealed significance for time to complete five of six tasks $(p$ $\leq .01$ ), with significantly more errors and unnecessary movements in 2 tasks. Study findings revealed the detriments of disturbed sleep on speed, error, and accuracy in a simulated environment.

Eastridge et al. (2003) compared 35 surgical residents' laparoscopic skills using a simulated surgery trainer during pre-call (rested) and post-call (acute) sleep deprivation 
sessions. Technical skills worsened post-call as compared to pre-call in number of errors (pre-call $p<.001)$ and time to complete tasks ( $p>.05$ pre-call). Subjective fatigue levels was significantly increased post-call $(p<.001)$. Results showed degradation in all 6 performance measures of simulated laparoscopic skills post call versus pre-call, correlating with increased subjective fatigue; contrary to the author's hypothesis that manual dexterity was not affected by sleep deprivation over a single call night.

Leff et al., (2008) focused on effects of circadian desynchronization across multiple shifts in residents' simulated surgical skills. They examined whether acute sleep deprivation would degrade 'difficult' simulated skills in surgical, obstetric, and emergency room residents over seven consecutive 12-hour night shifts $(N=21)$. Residents took significantly longer $(p=.002)$ and made more errors $(p=.025)$ on the first task compared to baseline during the $1^{\text {st }}$ night shift, and used more movements to complete the second task during the $1^{\text {st }}$ and $3^{\text {rd }}$ night shifts $(p=.009, p=.02$ respectively). By the $3^{\text {rd }}$ night shift, economy of movement, completion times, and error scores for either task improved to baseline. Subjective sleepiness scores increased subsequently over the week of night shifts. This study demonstrated that if sleep loss can be minimized and a 'circadian shift' can occur, performance adaptation may be possible. Interestingly, the lack of skill degradation after the $3^{\text {rd }}$ night shift was contrary to circadian and physiologic principles. Psychological (attitude), neurochemical (cortisol, acetylcholine, etc.), and physical adaptation (adjusting wake and sleep times), may have influenced an individual's performance; although the repetitive nature of the task may also have had some influence. 


\section{Brain Function Study}

A recent study examined the relationship of fatigue-induced performance against changes in brain function measured by functional near-infrared spectroscopy (Leff et al., 2010). Over a 10-hour acute-sleep-deprivation period (10:00pm to 8:00am), neurocognitive skills (arithmetic calculation), technical performance (time and number to complete surgical knot tying), and self-reported fatigue were measured. Activation of the prefrontal functions of the brain was required in cognitive, but not technical skills, despite increasing reports of subjective sleepiness. Although the total participant number was small $(\mathrm{N}=7)$, the study showed prefrontal recruitment, suggesting focused attention or compensation during acute sleep deprivation, may be a first step in medical error recognition if this process fails or when a technical procedure is unfamiliar to the acutelyfatigued individual.

\section{Fatigue Countermeasures in High-Risk Industries}

Personnel in safety-sensitive professions, such as aviation, firefighting, nuclear power, and the military require optimal performance at all times. Scott (2010a) found fatigue programs in these industries ill-suited to the healthcare field. Although a causal effect of healthcare worker fatigue and medical error has not been established, other industries have strict rules and safeguards to govern overtime and shift length to prevent errors and accidents.

The Aerospace Medical Association adopted Caldwell's 2009 position paper on "Fatigue countermeasures in aviation". It details aviation-specific problems to address fatigue of the aviation community. The paper addresses pre-/in-/post-flight 
countermeasures and management strategies, including the use of hypnotics; sleep hygiene and alertness practices; sleep-detecting technology and military aviation use of stimulants and sleep-inducing aids. Some of the strategies listed are non-pharmaceutical measures, which can be applicable to any high-risk organization, and can be adopted by an individual, versus a systems or culture change (which is beyond the scope of this study). Four main fatigue avoidance or prevention strategies are recommended. First, employ healthy sleep practices (quality, quantity, and environment for sleeping). Second, avoid alcohol, caffeine, and nicotine before bed. Third, establish a ritual, such as sleeping and awakening at the same time each day, and a bedtime routine. Last, take a prophylactic, 20-30 minute nap prior to the start of a long shift (although consider circadian phase of the body clock). Fatigue countermeasures, implemented when an individual is already fatigued, include: a) naps, b) activity breaks, (mild physical activity such as walking and increased social interaction), and c) workspace lighting to increase an alerting effect.

There is limited work-associated fatigue literature with nurses compared to medical trainees (interns and residents), and there are even fewer studies that examine countermeasures to prevent or combat fatigue while on the job. Scott et al. (2010b) designed a pilot study to evaluate the feasibility of a fatigue countermeasures program for nurse (FCMPN). A pre/post fatigue intervention program was implemented to promote hospital nurses sleep patterns, alertness, and decrease near or actual patient care errors. Baseline data was collected for two weeks prior to the one-hour education intervention, which was adapted from the National Aeronautical and Space Administration program 
and the American Academy of Sleep Medicine fatigue program for residents.

Countermeasures for the study included: adequate staffing so the study group nurses could take completely relieved breaks and mealtimes, and use of strategic naps during breaks and mealtimes. Nurses were also encouraged to adapt fatigue countermeasures at home and work (nap prior to an extended shift, obtain adequate sleep, etc.). Data was collected at 4-7 and 12 weeks. Full time hospital staff nurses participated $(N=147)$, onehalf receiving the intervention protocol; 47 nurses completed the study. Overall sleep duration, measured by log book, improved about 50 minutes four-weeks after the intervention ( $M=8.6$ hour, $S D=1.2$ hour) and was maintained at the 12 week post FCMPN report $(M=8.1$ hour, $S D=1.2$ hour). The Epworth Sleepiness Scale (Johns, 1991) suggested $48 \%$ of participants' experienced significant daytime sleepiness without improvement over the study period. Ninety-two episodes of drowsy driving was reported in 30 (of 47) participants. After the intervention, a decrease of $20 \%$ occurred at 4 weeks and $27 \%$ at 12 weeks; simultaneously, motor vehicle crashes or near-crashes decreased by $80 \%$. Finally, errors or near errors decreased in the 4 week post intervention period significantly $(p=.01)$, leveling at12 weeks $(p=.06)$. Fatigue education, managerial support, adequate staffing, and a willingness to participate (nurses expressed guilt for napping during a shift), may improve nurse and patient outcomes. The authors suggest a shared responsibility for fatigue-reduction strategies among nurses and administrators and a restriction of additional employment of full-time nurses to decrease adverse consequences to the patient error and the nurse. 


\section{Patient Care Error}

Definitions of the patient care movement are similar but not agreed upon between the IOM, AHRQ, and patient safety organizations such as the National Patient Safety Foundation. This study focuses on the IOM's report to reduce fatigue-related medical error therefore; definitions used will be from that report (Kohn et al., 2000). A medical error is the failure of an action to be completed as intended (whether during execution or planning); an adverse event is "an injury resulting from a medical intervention", and a near miss is an error not resulting in harm. Woodward and associates (2010) provide a summary of error reduction strategies in the order likely to gain the most benefit. The highest level of strategy is the use of tools and procedures making the occurrence of an error or adverse event difficult. Standardized work processes are considered an intermediate measure and the weakest strategy focuses on education that directs human behavior. The first two strategies would be most useful in providing the 'safest' environment for a fatigued healthcare worker.

Stone et al. (2006) collected data from surveys, patient records, and administrative records in a study that compared effects of 8 and 12-hour shifts on nursing, the institution (turnover, absenteeism, etc.), and quality patient outcomes. The authors decided since adverse events were underreported, patient care outcomes would be measured using 12months of incident reports, patient discharge abstracts, and nurses' perceptions of quality. The results reflected nurses who worked 12-hour shifts were more satisfied with their jobs, had less emotional exhaustion, were 10 times more likely to be satisfied with schedules and $58 \%$ less likely to miss a shift. There were no differences in patient 
outcomes in the 8 versus 12 -hour shifts. In this study, increasing shift length from 8 to 12 hours produced 10 times more nursing satisfaction, less emotional exhaustion, 58\% less missed shifts, and two times the likelihood to perceive 12 hour shifts were important

(all $p$ values $<.05$ ) without a negative consequence for quality patient outcomes. Positive psychological influences, possible time-saving time in total commute time, work preparation, working three 12 hour days per week versus five, less patient turnover (two versus three handoffs), and perception the 12 hour shift is important, may have influenced the outcomes. On the contrary, other studies (Rogers et al., 2004; Trinkoff et al., 2007) found although nurses were scheduled to work 12-hour shifts, at least a quarter work longer with detrimental outcomes to the nurse and patients.

Rogers and associates (2004) reported nurses working longer than 12-hours, those who worked overtime, or those working more than 40 hours per week made more errors. Nearly 400 hospital nurses from hospitals nationwide revealed that $40 \%$ of their shifts exceeded 12 hours. Notably, almost two-thirds of nurses worked overtime at least 10 times over the 28 -day study period and in nearly $10 \%$ of those, nurses were either mandated or 'coerced' into staying longer. Risks of errors was three times higher when nurses worked greater than 12.5 hours (odds ratio $=3.29, p=.001$ ) and was significantly elevated when working overtime following a 12-hour shift $(p=.005)$.

\section{Conceptual Framework}

The middle-range theory of unpleasant symptoms (Lenz et al., 1997) is a conceptual pathway for fatigue influences: physiologic, psychological, and situational factors, which can produce chronic or acute health symptoms and affect performance. 
The original theory originated with the collaboration of three separate investigators. Authors Pugh and Milligan were separately studying fatigue in different perinatal phases and developed a model of fatigue during childbirth (Lenz, Suppe, Gift, Pugh, \& Milligan, 1995). Simultaneously, Gift and Pugh recognized that the concepts of fatigue and the physiological aspects of dyspnea had a generality in the experience of the individual (Lenz et al., 1995). The authors combined their models to include a broad clinical population with similar concepts that resulted in situational, physiological or psychological factors of experiencing an event (childbirth fatigue or dyspnea). They developed a general middle-range theoretical framework called the theory of unpleasant symptoms. Three components comprise the model: symptoms of the experience (i.e. fatigue), factors which affect the symptom (situational, physiological or psychological influences) and consequences to the individual's performance (Lenz et al., 1995). In 1997, an updated version included multiple symptoms recognizing that a preceding symptom (i.e. fatigue), could result in another symptom (i.e. nausea) (Lenz et al., 1997). Occasionally symptoms take place in isolation but more often, multiple symptoms occur together. Symptoms can be a multidimensional experience and can be measured in isolation or with other symptoms. Even though symptoms may be unique, common dimensions of all symptoms and clinical populations are the intensity, timing, perceived level of distress, and effect on the individual. See Figure 1.

In summary, the circadian pacemaker controls the endogenous sleep-wake pattern in humans, is sensitive to bright light, and controls nearly all physiologic and behavioral variables promoting alertness and performance during the day (Barger et al., 2009). The 
middle-range theory of unpleasant symptoms (Lenz et al., 1997), accounts for fatigues physiological and behavioral variables of influence. Physiological effects of the circadian rhythm, psychological effects such as the stress of being on call, and situational demands (work load, vigilance, etc.), are multifactorial components which can result in the experience of acute (or chronic) health symptoms and affect performance. Just as bright light has been shown to reduce sleepiness, increase alertness, suppress melatonin, and increase core body temperature and heart rate (Ruger et al., 2006), examining each of fatigue's influencing factors may preclude using other means to gain the same result (use of countermeasure to increase core temperature and heart rate, etc.). 


\section{CHAPTER 3}

\section{METHODOLOGY}

The purpose of this study was to examine whether Certified Registered Nurse Anesthetists (CRNAs) experience fatigue during call and to assess their use of fatigue avoidance strategies (practices that prevent fatigue) and fatigue countermeasures (practices that decrease fatigue) to mitigate its effects. The middle-range theory of unpleasant symptoms (Lenz, et al., 1997) is a conceptual pathway for the contributing factors of fatigue and was used as the theoretical basis for the study (Appendix A). This chapter presents a description of the research methodology including study aims, study design, sample and sampling, instrumentation, data collection procedures, data analysis, and the protection of human subjects.

\section{Methods}

Aims of the Study.

Aim 1. To characterize fatigue experience by duration of call, use of fatigue avoidance strategies to prevent fatigue prior to call, and use of fatigue countermeasures during call, among a national sample of CRNAs. 
Aim 2. To examine the relationships between fatigue experience, duration of call (weekday or weekend), call days per month, anesthesia days per week, occurrence of physiological or psychological symptoms, use of fatigue avoidance strategies, fatigue countermeasures, and selected demographics among a national sample of CRNAs.
Aim 3.
To explore factors related to the odds of experiencing fatigue during call.

Design. A cross sectional descriptive survey design was used for this study. Survey research designs are both a design and a data collection method (Burns \& Grove, 2001). Creswell (2009) argues they are best for describing attitudes and opinions. Although surveys, as a research design, are controversial because the limited data obtained is shallow and may not add significantly to scientific knowledge, a carefully thought out survey can provide very useful and representative information (Meadows, 2003). Descriptive designs are employed when the researcher wishes to obtain information about phenomena in which little investigation has occurred (Kerlinger \& Lee, 2000). A review of the literature found no empirical studies on CRNAs experience of call shift fatigue and the use of fatigue avoidance strategies or fatigue countermeasures. The increasing empirical evidence on the effects of fatigue from extended shift lengths and its relationship to patient care error and healthcare worker injury underscores the need to examine the experience of call shift fatigue and the use of fatigue avoidance strategies and countermeasures to improve patient care outcomes. 


\section{Procedures}

Sample. The sample consisted of American Association of Nurse Anesthetist (AANA) members. The AANA is the professional organization of CRNAs with a membership of 40,000 , which is nearly $90 \%$ of all practicing CRNAs (AANA, 2010). The AANA website defines a CRNA as an advanced practice nurse specializing in anesthesia, who has received 24 to 36 months of graduate training, and passed the certification examination to practice. The study protocol was (a) reviewed and approved by the institutional review board at the University of San Diego (Appendix B), and (b) approved for distribution by the AANA. Potential participants $(\mathrm{N}=2,500)$ were recruited via an email invitation generated by a paid web survey company contracted by the AANA. The AANA provides this fee-for-service access to any AANA member, who meets approved criteria, to send out a survey based on desired participant characteristics (CRNAs who answered their character profiles, i.e., active practice status, age, work hours, etc.). For this study, inclusion criteria were male and female members in active practice with previously completed AANA demographic questionnaires. This economical web-based, self-administered survey was selected to enable the researcher access to a large sample size without increasing expense, as well as, for participant convenience including the ability to respond at a time convenient for them. The e-mail distribution number was calculated from the expected return online survey rate which varied from $37 \%$ according to Sheehan (2001), to a large range of $6-68 \%$ recorded by Schonlau, Fricker, and Elliott (2002). Older literature predicted mail survey response 
rates between 5-10\% (Alreck \& Settle, 1995). Using the lower end of the predicted response rate of about $10 \%, 2,500$ email invitations were randomly generated to obtain a desired sample size of 250 completed surveys.

Sample Size. There is no consensus on the approach to compute power and sample size with logistic regression; although as pointed out by Katz (1999), 10 outcomes for each independent variable is appropriate. In logistic regression an estimate of the probability of a certain event occurring is made, rather than detecting the difference or relationship that may be present, such as in linear regression. No assumptions are made about the dependent variable (DV) and independent variable (IV), the relationship is nonlinear, and is not normally distributed (Munro, 2005). The likelihood ratio test, the test on proportions, and various approximations to handle the multivariate case have been used. The use of the Wald test is often advocated, since the Z-score is routinely used for statistical significance testing of regression coefficients (Demidenko, 2007). This is a descriptive study and not focused on hypothesis testing. Thus the Final Logistic Regression Model, which includes statistical significance defined by $p<0.05$, where $p$ is from the Wald test for Confidence Interval for the Odds ratio and overall statistical significance is tested by the likelihood ratio test, $p<0.1$, was used to demonstrate logistic regression model fit (Mertler \& Vannatta, 2010).

Instrumentation and Data Collection. A 26-item survey was developed by the investigator to elicit data on CRNAs' fatigue experience and their use of fatigue interventions before and during call (Appendix C). The survey items were derived from the literature and clinical experience. Items included rated-responses and open-ended 
questions. A panel comprised of a fatigue expert and three doctorally prepared nurse scientists were consulted to establish content validity. Utilizing the panel's feedback, questions were deleted or improved to obtain information about how fatigue may affect practice. Open-ended questions were added to gain more in-depth information related to the questions.

The survey was pilot tested using a group of six CRNAs prior to administering to the national population. Several participants suggested changes related to purpose, clarity, content, technical issues, and layout. Definitions were added to distinguish a fatigue avoidance strategy versus a fatigue countermeasure, and additional questions were added to address the phenomena of fatigue, for example, 'do you think fatigue is a problem in the community'?

To avoid participant and financial burden the final survey contained 26 questions related to a) call shift length and frequency, b) strategies used to prevent fatigue prior to call, c) use of fatigue countermeasures during call, d) having made a patient care error due to fatigue, and e) if they experienced any health symptoms while fatigued. A few questions were directed toward previously deployed military CRNAs to determine if they felt they had adequate time for sleep and if fatigue was an issue. A final open-ended question invited participants to add information they wished to convey (See Appendix C, Page 6). Demographic data including age, gender, and military deployment in a CRNA role were collected.

\section{Measurement}

Fatigue. Fatigue is a common symptom of normal physiologic and psychologic 
response to exertion or stress. Stedman's Medical Dictionary (2005) defines fatigue as a state, after a period of mental or physical activity, of lessened capacity or motivation for work or efficiency, usually accompanied by weariness, irritability and sleepiness.

Fatigue may also arise unexpectedly, from any cause, when energy expenditure exceeds a person's capability. In this study, fatigue is defined as 'a feeling of mental or physical exhaustion, beyond being tired as a result of continued stimulation'. It is assessed by the question “Do you experience fatigue during call?" (Question 6, Table 1).

Fatigue Avoidance Strategies. Fatigue Avoidance Strategies include healthy sleep practices, avoidance of stimulants before bed, going to sleep and awakening at the same time each day, and taking a nap prior to a long shift. These strategies are based on the most recently released aviation fatigue intervention recommendations, which can apply across multiple disciplines (Caldwell et al., 2009). The question was "What fatigue avoidance strategies do you use prior to call to avert fatigue?" (Question 7, Table 1).

Fatigue Countermeasures. Fatigue countermeasures are implemented when an individual experiences fatigue and include tactics such as naps, activity breaks (to include mild physical activity such as walking and increased social interaction), increasing lighting intensity, and use of stimulants (Caldwell et al., 2009). The survey asked, "When you experience fatigue, what fatigue countermeasures do you use to minimize the effects?" (Question 9, Table 1).

Demographics. Survey demographic characteristics include age, gender, and military service (Table 1). 


\section{Data Collection}

The researcher presented an overview of the study, predicted time commitment to complete the survey, and information of how to contact the researcher or her chairperson in a cover letter, which opened as an email message (Appendix D). If the CRNA was interested in participating, a link at the bottom of the message would open the survey. The survey consent was explained in the opening email message and if the participant chose to open the survey link, implied consent was obtained.

Data were collected over a four-week period. The initial mailing was November 18 and two weeks later, a repeat invitation was sent to those who did not initially complete the survey. The survey was open from November 18 through Dec 20, 2010. Since a greater than $10 \%$ response rate was achieved after the second mailing, the survey was closed two weeks later $(\mathrm{N}=388)$.

Data Management and Analysis. Data were analyzed using the SPSS 17.0 program. Pre-analysis data screening and cleaning was conducted to identify and correct common problems that can influence the accuracy of the analysis. Initially tables showing the variables frequency distribution, mean, range, percentage, and standard deviations described the sample and provided an overview of the data. Analytic procedures included a descriptive analysis of the variables and inferential statistics for testing the research questions. Prior to the analysis the variable for fatigue experience was coded as rare ('occasionally' and 'rarely' $=0$ ), and frequently ('frequently' and 'often' = 1). Shift length (weekdays and weekends), was recoded from five to two values $(\leq 15,16$, 
$17-23,24$ and $>25$ hours) to $\leq 16=0$ or $>17$ hours $=1$; the number of fatigue avoidance strategies and the number of CMs were recoded from five to two values $(0$ to $>4)$ to $\leq 2=$ 0 or $\geq 3=1$; the anesthesia days per week was collapsed from five to three values $(<3$ to 7 days) to $\leq 4=0,5=1, \geq 6=2$; finally, calls per month was collapsed from five to three values $(0-4=0,5-8=1,>9=2)$.

The majority of open-ended questions inquired about associated factors of fatigue using the theoretical model constructs (physiological, psychological, and situational related). Those responses were coded using the most appropriate factor and constant comparison method. The table below describes the survey dimensions and variable categories. 
Table 1

Survey Dimensions and Variable Category

\begin{tabular}{|c|c|c|c|}
\hline Dimension & Questions & Variable & Level of Data \\
\hline Call & 1. Do you participate in call? & Independent & Binary \\
\hline Duration & $\begin{array}{l}\text { 2. Weekday } \\
\text { 3. Weekend }\end{array}$ & Independent & Ordinal \\
\hline Calls/month & 4. Average calls per month & Independent & Ordinal \\
\hline $\begin{array}{c}\text { Days of } \\
\text { anesthesia }\end{array}$ & $\begin{array}{l}\text { 5. Average \# days doing } \\
\text { Anesthesia }\end{array}$ & Independent & Interval \\
\hline Call fatigue & $\begin{array}{l}\text { 6. Experience of fatigue } \\
17 . \text { Is fatigue common }\end{array}$ & $\begin{array}{c}\text { Dependent } \\
\text { Nominal }\end{array}$ & Ordinal \\
\hline $\begin{array}{l}\text { Fatigue avoidance } \\
\text { strategies (FASs) }\end{array}$ & $\begin{array}{l}\text { 7. List FAS's in order of } \\
\text { frequency } \\
\text { 8. Most effective } \\
\text { 11. Number FAS's before call }\end{array}$ & Independent & $\begin{array}{l}\text { Nominal } \\
\text { Nominal } \\
\text { Interval }\end{array}$ \\
\hline $\begin{array}{l}\text { Fatigue counter- } \\
\text { measures (CMs) }\end{array}$ & $\begin{array}{l}\text { 9. List CM's used in order of } \\
\text { frequency } \\
\text { 10. Most effective } \\
\text { 12. Number CM's during call. } \\
\text { 15. If need to do anesthesia } \\
\text { while fatigued, use a CM? }\end{array}$ & Independent & $\begin{array}{l}\text { Nominal } \\
\text { Nominal } \\
\text { Interval } \\
\text { Binary }\end{array}$ \\
\hline $\begin{array}{c}\text { Number of hours } \\
\text { awake }\end{array}$ & $\begin{array}{l}\text { 13. Prior to call } \\
\text { 14. After starting call }\end{array}$ & Independent & $\begin{array}{l}\text { Interval } \\
\text { Interval } \\
\end{array}$ \\
\hline Patient error & 16. Error related to fatigue & Dependent & Binary \\
\hline Call recovery & 18. Hours to recover from call & Independent & Interval \\
\hline $\begin{array}{l}\text { Physiological / } \\
\text { psychological } \\
\text { symptoms }\end{array}$ & 19. Experience of symptoms & Independent & Binary \\
\hline Demographics & $\begin{array}{l}\text { Military CRNAs (\#20-23) } \\
\text { 20. Days deployed } \\
\text { 21. Adequate time for sleep } \\
\text { 22. Error from fatigue related } \\
\text { to deployment } \\
\text { 23. Fatigue common during } \\
\text { deployment } \\
\text { 24. Age } \\
\text { 25. Gender }\end{array}$ & Independent & $\begin{array}{c}\text { Interval } \\
\text { Binary } \\
\text { Binary } \\
\text { Nominal } \\
\text { Interval } \\
\text { Nominal }\end{array}$ \\
\hline $\begin{array}{l}\text { Additional } \\
\text { information }\end{array}$ & $\begin{array}{l}\text { 26. Open ended question } \\
\text { expressing fatigue effects }\end{array}$ & Independent & Nominal \\
\hline
\end{tabular}


Aim 1. To characterize fatigue experience by duration of call, use of fatigue avoidance strategies to prevent fatigue prior to call, and use of fatigue countermeasures during call, among a national sample of CRNAs.

Question 1. What are the characteristics of fatigue experience, duration of call, use of fatigue avoidance strategies to prevent fatigue prior to call, and use of fatigue countermeasures among a national sample of CRNAs?

Descriptive statistics were computed to describe the characteristics of fatigue experience, call duration, use of fatigue avoidance strategies, and fatigue countermeasures. Measures of central tendency with the mean, median, standard deviation, and frequency of outcomes were summarized.

Aim 2. To examine the relationships between fatigue experience, duration of call, occurrence of physiological or psychological symptoms, use of fatigue avoidance strategies, fatigue countermeasures, and selected demographics.

Question 2. What are the relationships between fatigue experience, duration of call (weekday or weekend), occurrence of physiological or psychological symptoms, use of fatigue avoidance strategies, fatigue countermeasures, age, and gender among a national sample of CRNAs? 
Chi square for nominal variables were used to examine the relationships between the fatigue variables and demographic variables. An analysis of variance test (ANOVA) test was conducted to determine if there were differences in age based on CRNAs experience of fatigue.

Aim 3. To explore factors related to the odds of experiencing fatigue during call.

Question 3. Are there predictor variables related to the odds of experiencing fatigue during call?

Logistic regression is used to accurately predict the probability, ranging from 0 to 1 , of a particular outcome being grouped into one category (rare fatigue $=0$ ) or another (frequent fatigue $=1$ ), for each subject (Mertler \& Vannatta, 2005). Logistic regression is a multivariate statistical analysis that can be used to predict membership in one dichotomous variable from a set of independent variables. This method is chosen over discriminate analysis and multiple regression, as data from continuous, discrete, and dichotomous variables can be used and there are no assumptions about the distribution of the predictor variables (Mertler \& Vannatta, 2005). The tolerance statistic in the SPSS software can examine mulitcollinearity among the independent variables to insure that they do not measure the same thing. Tolerance statistics less than 0.10 would suggest a collinearity problem within the identified independent variables (Mertler \& Vannatta, p. 169,2005 ) and would require re-examination of predictor variables for inclusion in the study. Factors analyzed include duration of call shift (weekday and weekends), 
occurrence of physiologic and psychological symptoms, use of FASs, fatigue CMs, days per week of anesthesia, calls per month, gender, and age.

\section{Protection of Human Subjects}

Every effort was made to maintain participant confidentiality. Participants were assured participation was voluntary and refusal to answer questions would not affect their job or AANA membership. They were made aware their responses would be kept confidential, they were asked not to provide identifying information when completing the survey questions and were informed that only aggregate data from the survey would be reported (Appendix D). 


\section{CHAPTER 4}

\section{RESULTS}

The purpose of this study was to examine whether Certified Registered Nurse Anesthetists (CRNAs) experience fatigue during call and to assess their use of fatigue avoidance strategies (practices that prevent fatigue) and fatigue countermeasures (practices that decrease fatigue) to mitigate its effects. This chapter will present the study findings. First, a description of the sample is provided followed by results related to the research questions.

\section{Characteristics of the Sample}

Data were collected via an on-line electronic survey randomly distributed to 2,500 members of the American Association of Nurse Anesthetists (AANA) from November to December of 2010. Of 388 participants who opened the survey, 347 provided usable data, $(14 \%)$, and of those, only data of those who participated in taking call $(n=323)$ were analyzed.

The sample was fairly evenly distributed by gender, with slightly more female $(55 \%, \mathrm{n}=179)$ than male respondents, which is consistent with AANAs membership of

$59 \%$ female (AANA, 2011). Ages ranged from $29-73$ years old $(M=47.9, S D 10.25)$. Table 2. 
Slightly more than half $(53.8 \%, \mathrm{n}=174)$ who worked weekday call, reported $\leq 16$ hour call shifts, and $122(37.7 \%)$ reported $17-24$ hour call shifts. Less than $10 \%(\mathrm{n}=$ 26) reported their call shifts were $>25$ hours. Of those who worked a weekday call, only 33 worked more than one different shift length during the week, 22 worked two different shift lengths, and the remainder worked 3 or 4 different weekday shift lengths. For weekend call, $74.5 \%$ reported shifts of 17 hours or greater. Of those who worked a weekend, only 31 worked more than one different shift length during the weekend; 24 worked two different shifts, and the remainder worked 3 or 4 different weekend shift lengths. Those who worked two different weekend call shift lengths seemed to work the longest shift lengths, 24 and $>25$ hour call shifts $(n=10)$. In an average week, including call, $43 \%(n=139)$, worked 5 days a week, $45 \%(n=146)$ worked 4 days or less, and $12 \%$ worked 6 or 7 days per week.

When asked about the experience of fatigue during call, approximately $11 \%(\mathrm{n}=$ 35) reported experiencing fatigue 'often', defined as nearly every call, a third $(32.2 \%, \mathrm{n}=$ 104) reported 'frequently' (once/month), 39\% $(\mathrm{n}=126)$ reported 'occasionally' (4 times/year), and 18\% $(\mathrm{n}=58)$ reported 'rarely' experiencing fatigue (once/year). Seventy-three percent thought CRNA fatigue is common. Approximately two thirds $(66.5 \%, \mathrm{n}=215)$ experienced physical/psychological symptoms and $91(28 \%)$ have committed a patient care error due to fatigue. Fatigue avoidance strategies and countermeasures were used by $77 \%(n=249), 87 \%(n=281)$ CRNA respondents respectively. See Table 2. 
Table 2

Summary of Demographic and Study Variable Characteristics

\begin{tabular}{|c|c|}
\hline Characteristic & n (\%) \\
\hline \multicolumn{2}{|l|}{ Gender } \\
\hline Female & $179(55.2)$ \\
\hline Male & $145(44.8)$ \\
\hline Age & $47.9(S D$ 10.3, Range 29 - 73) \\
\hline \multicolumn{2}{|l|}{ Call shift length } \\
\hline Weekday $\leq 16$ hours & $174(53.8)$ \\
\hline Weekday $17-24$ hours & $122(37.7)$ \\
\hline Weekday $>25$ hours & $26(8.0)$ \\
\hline Weekend $\leq 16$ hours & $80(24.7)$ \\
\hline Weekend $17-24$ hours & $123(38.0)$ \\
\hline Weekend $>25$ hours & $118(36.5)$ \\
\hline \multicolumn{2}{|l|}{ \# anesthesia days per week (including call) } \\
\hline$\leq 3$ days & $55(17 \%)$ \\
\hline 4 days & $91(28 \%)$ \\
\hline 5 days & $139(43 \%)$ \\
\hline 6 days & $24(7.4 \%)$ \\
\hline 7 days & $13(4.0 \%)$ \\
\hline \multicolumn{2}{|l|}{ Experience fatigue during call } \\
\hline Rarely (once/year) & $58(18.0)$ \\
\hline Occasionally (4/year) & $126(39.0)$ \\
\hline Frequently (once/month) & $104(32.2)$ \\
\hline Often (nearly every call) & $35(10.8)$ \\
\hline \multicolumn{2}{|l|}{ Do you think CRNA fatigue is common } \\
\hline No & $32(9.9)$ \\
\hline Yes & $236(73.1)$ \\
\hline Do not know & $55(17.0)$ \\
\hline \multicolumn{2}{|l|}{ Physical or psychological symptoms when fatigued } \\
\hline No & $64(19.8)$ \\
\hline Yes & $215(66.5)$ \\
\hline No Response & $44(13.6 \%)$ \\
\hline \multicolumn{2}{|l|}{ Committed an error in patient care because of fatigue } \\
\hline No & $222(68.7)$ \\
\hline Yes & $91(28.2)$ \\
\hline Not Sure/refuse to answer & $10(3.1)$ \\
\hline \multicolumn{2}{|l|}{ Fatigue avoidance strategies (FAS) } \\
\hline \# who use a FAS & $249(77.0)$ \\
\hline Average \# used prior to call & 1.30 (SD 0.958, Range $0-4)$ \\
\hline \multicolumn{2}{|l|}{ Fatigue countermeasures $(\mathrm{CM})$} \\
\hline \# who use a fatigue $\mathrm{CM}$ & $281(87.0)$ \\
\hline Average \# used during call & $1.65(S D 1.02$, Range $0-4)$ \\
\hline
\end{tabular}

Note: $\mathrm{N}=323$ 
There were four questions inquiring about the experience of fatigue during military deployment. Thirty-three (9\%) of the respondents answered questions about being formerly deployed as a military CRNA. Nearly half (45\%) reported being deployed for more than 181 days, $47 \%$ reported fatigue is common during deployment ( $\mathrm{n}$ $=17)$, yet $55 \%(n=18)$ reported having adequate time for sleep. See Table 3.

Table 3

Summary of Military Deployment Experience of Fatigue

\begin{tabular}{|l|l|}
\hline Number of respondents & $\mathbf{n}(\%)$ \\
\hline Number of days deployed & $13(39.4)$ \\
$\leq 90$ & $5(15.2)$ \\
$91-180$ & $15(45.4)$ \\
$\geq 181$ & \\
\hline Adequate time for sleep to perform anesthesia safely & $4(12.1)$ \\
No & $18(54.5)$ \\
Yes & $11(33.3)$ \\
Sometimes & \\
\hline Ever committed error in patient care related to fatigue* & $30(90.9)$ \\
No & $2(6.1)$ \\
Yes (already explained) & $1(3.0)$ \\
Yes (different occasion) & \\
\hline Is fatigue common during deployment & $4(11.1)$ \\
No & $17(47.2)$ \\
Yes & $15(41.7)$ \\
Do not know & \\
\hline
\end{tabular}

* Respondents were asked if they already explained the event in a previous question. Note: $\mathrm{N}=33$

\section{Coding Fatigue Interventions}

Using the theoretical model depicting the factors' that can be associated with fatigue (physiological, psychological, and situational), the open-ended question responses were coded using the most appropriate factor and constant comparison. From three fatigue-associated factor groups, seven themes emerged. The physiological factor group had three themes which influence fatigue: 'fatigue prevention', encompasses 
tactics including sleeping longer the day prior to or day of call, taking a nap prior to call, etcetera; 'nutritional influences' such as eating small meals, eating snacks, or drinking coffee or caffeine, and 'exercise'. Respondents $(\mathrm{n}=18)$ commented that maintaining a healthy lifestyle (getting regular sleep, rest, and healthy food) were part of their fatigue avoidance strategies. The second factor group included psychological measures of 'stress reduction' such as deep breathing, finding a quiet place to relax, and focusing on the job. Finally, the situational factor group of fatigue avoidance strategies were divided into two groups: One was labeled as actions that could 'decrease the occurrence of fatigue', such as delegating work, taking lighter cases when possible, sitting rather than standing, taking a break, and to 'keep busy' by reading a book, searching the internet, or calling family or friends. Finally, a cohort of subjects answered 'not applicable' or 'does not apply' as they are not called in often or simply do not experience fatigue during call $(n=27)$.

Over two thirds $(67 \%, \mathrm{n}=217)$ used the physiological fatigue factor group of 'fatigue prevention' methods including sleeping longer the night prior and taking naps prior to call, as the primary fatigue avoidance strategy (FAS). The next two most frequently used FASs were also grouped under the physiological factor domain: Nutrition (i.e. eating a balanced diet, avoiding alcohol the night prior, etc.) $11 \%(\mathrm{n}=$ $36)$, and exercise or being active $7 \%(\mathrm{n}=21)$. Two hundred and three subjects used at least two fatigue avoidance strategies (FASs). More than one half $(60 \%, \mathrm{n}=122)$ used two 'fatigue prevention' strategies (sleep longer than usual the night prior and nap before call, or a fatigue prevention strategy and either nutrition (i.e. eating a balanced diet, 
drinking caffeine $(27 \%, \mathrm{n}=55)$, or exercise $(11 \%, \mathrm{n}=23)$. One hundred sixteen reported using 3 to 4 FASs, and six listed 5 strategies. Participants were asked to list, in order, the FAS they used most frequently. Subjects listed the top two most effective FAS as fatigue prevention $(67 \%, \mathrm{n}=215)$ and exercise $(9 \%, \mathrm{n}=28)$, while 38 CRNAs $(12 \%)$ stated nothing was effective or it did not apply to them. Interestingly, in a separate question, when asked to give a number of how many fatigue avoidance strategies subjects used prior to call, $120(37 \%)$ answered one, yet 203 persons listed at least two FASs in a previous question.

The same fatigue influencing factors (physiological, psychological, and situational) were used to categorize the open-ended question inquiring about the use of fatigue countermeasures. A countermeasure (CM) was defined as an action to oppose the effects of fatigue. Slightly less than half $(46 \%, n=148)$ used the physiological factor domain of nutrition with fatigue prevention listed second in that grouping $(12 \%, n$ $=40$ ). The second largest domain listed was situational CM tactics of keeping busy $(24 \%, n=78)$. One hundred eighty-eight CRNAs used two fatigue CMs, $23 \%(n=44)$ used CMs in two domains: physiologic (specifically nutrition) and situational (keeping busy). One hundred twenty four CRNAs reported using 3 to $4 \mathrm{CMs}$ while five persons listed 5 strategies. Frequencies for fatigue interventions are summarized in Tables 3 and 4. 
Table 4

Frequencies for Fatigue Avoidance Strategies

\begin{tabular}{|c|c|}
\hline Fatigue avoidance strategies most frequently used & $\mathrm{n}(\%)$ \\
\hline \multicolumn{2}{|l|}{ Physiologic Factors } \\
\hline Fatigue prevention (sleep longer day prior, nap before call) & $217(67.2)$ \\
\hline Nutrition \& caffeine (pack a meal, snack, caffeine) & $36(11.1)$ \\
\hline Exercise (before call, run stairs, walk outside) & $21(6.5)$ \\
\hline \multicolumn{2}{|l|}{ Psychological Factors } \\
\hline Stress reduction (deep breathing, quiet place to relax, focus only on the job) & $6(1.9)$ \\
\hline \multicolumn{2}{|l|}{ Situational Factors } \\
\hline Decrease workload (delegate work, take light cases or a break if possible) & $12(3.7)$ \\
\hline Keep busy (read, internet, or phone call) & $4(1.2)$ \\
\hline Not applicable/No fatigue & $27(8.4)$ \\
\hline \multicolumn{2}{|l|}{ Strategies listed as a second fatigue avoidance strategy $(n=203)$} \\
\hline \multicolumn{2}{|l|}{ Physiologic Factors } \\
\hline Fatigue prevention & $69(34.0)$ \\
\hline Nutrition \& caffeine & $70(34.5)$ \\
\hline Exercise & $29(14.3)$ \\
\hline \multicolumn{2}{|l|}{ Psychological Factors } \\
\hline Stress reduction & $8(3.9)$ \\
\hline \multicolumn{2}{|l|}{ Situational Factors } \\
\hline Decrease workload & $19(9.4)$ \\
\hline Keep busy & $8(3.9)$ \\
\hline \multicolumn{2}{|l|}{ Most effective fatigue avoidance strategy } \\
\hline \multicolumn{2}{|l|}{ Physiologic Factors } \\
\hline Fatigue prevention & $215(66.6)$ \\
\hline Nutrition \& caffeine & $18(5.6)$ \\
\hline Exercise & $28(8.7)$ \\
\hline \multicolumn{2}{|l|}{ Psychological Factors } \\
\hline Stress reduction & $9(2.8)$ \\
\hline \multicolumn{2}{|l|}{ Situational Factors } \\
\hline Decrease workload & $4(1.2)$ \\
\hline Keep busy & $8(3.9)$ \\
\hline Not applicable/No fatigue & $38(11.8)$ \\
\hline
\end{tabular}


Table 5

Frequencies for Fatigue Countermeasures

\begin{tabular}{|c|c|}
\hline Fatigue Countermeasures most frequently used & $N(\%)$ \\
\hline \multicolumn{2}{|l|}{ Physiologic Factors } \\
\hline Fatigue prevention (sleep, nap when possible) & $40(12.4)$ \\
\hline Nutrition \& caffeine (small meals, snack, caffeine) & $148(45.8)$ \\
\hline Exercise (jumping jacks, pushups, be active) & $9(2.8)$ \\
\hline \multicolumn{2}{|l|}{ Psychological Factors } \\
\hline Stress reduction (stay calm, 'down time') & $4(1.2)$ \\
\hline \multicolumn{2}{|l|}{ Situational Factors } \\
\hline Decrease workload (sit vs. stand, take breaks) & $19(5.9)$ \\
\hline Keep busy (talk, walk around, surf internet) & $78(24.1)$ \\
\hline Not applicable/No fatigue & $25(7.7)$ \\
\hline \multicolumn{2}{|c|}{ Countermeasures listed as a second fatigue countermeasure $(n=188)$} \\
\hline \multicolumn{2}{|l|}{ Physiologic Factors } \\
\hline Fatigue prevention & $20(10.5)$ \\
\hline Nutrition \& caffeine & $55(29.3)$ \\
\hline Exercise & $12(6.4)$ \\
\hline \multicolumn{2}{|l|}{ Psychological Factors } \\
\hline Stress reduction & $3(1.6)$ \\
\hline \multicolumn{2}{|l|}{ Situational Factors } \\
\hline Decrease workload & $18(9.6)$ \\
\hline Keep busy & $80(42.6)$ \\
\hline \multicolumn{2}{|l|}{ Most effective fatigue countermeasure } \\
\hline \multicolumn{2}{|l|}{ Physiologic Factors } \\
\hline Fatigue prevention & $60(18.6)$ \\
\hline Nutrition \& caffeine & $82(25.4)$ \\
\hline Exercise & $23(7.1)$ \\
\hline \multicolumn{2}{|l|}{ Psychological Factors } \\
\hline Stress reduction & $7(2.2)$ \\
\hline \multicolumn{2}{|l|}{ Situational Factors } \\
\hline Decrease workload & $28(8.7)$ \\
\hline Keep busy & $83(25.7)$ \\
\hline Not applicable/No fatigue & $40(12.4)$ \\
\hline
\end{tabular}




\section{Research Aims and Questions}

Aim 2. To examine the relationships between fatigue experience, duration of call (weekday or weekend), call days per month, anesthesia days per week, occurrence of physiological or psychological symptoms, use of fatigue avoidance strategies, fatigue countermeasures, and selected demographics among a national sample of CRNAs.

Question 2. What are the relationships between fatigue experience, duration of call (weekday or weekend), call days per month, anesthesia days per week, occurrence of physiological or psychological symptoms, use of fatigue avoidance strategies, fatigue countermeasures, age, and gender among a national sample of CRNAs?

An analysis of variance test (ANOVA) test was conducted to determine if there were differences in age based on CRNAs experience of fatigue. CRNA fatigue experience was categorized into rarely, occasionally, frequently, and often. There were no significant differences in age between the fatigue categories, however, there was a trend towards increased fatigue as CRNAs aged $(\mathrm{p}=0.057)$, Figure 2. However, examining age by fatigue experience (rare or frequent) there were significant mean age differences by $C R N A s$ experiencing rare fatigue $(M=46.72, S D=10.25)$ and frequent fatigue $(M=49.37, S D 10.12), F(1,322)=5.35, p=.02$. 
Figure 2

Experience of Fatigue During Call*

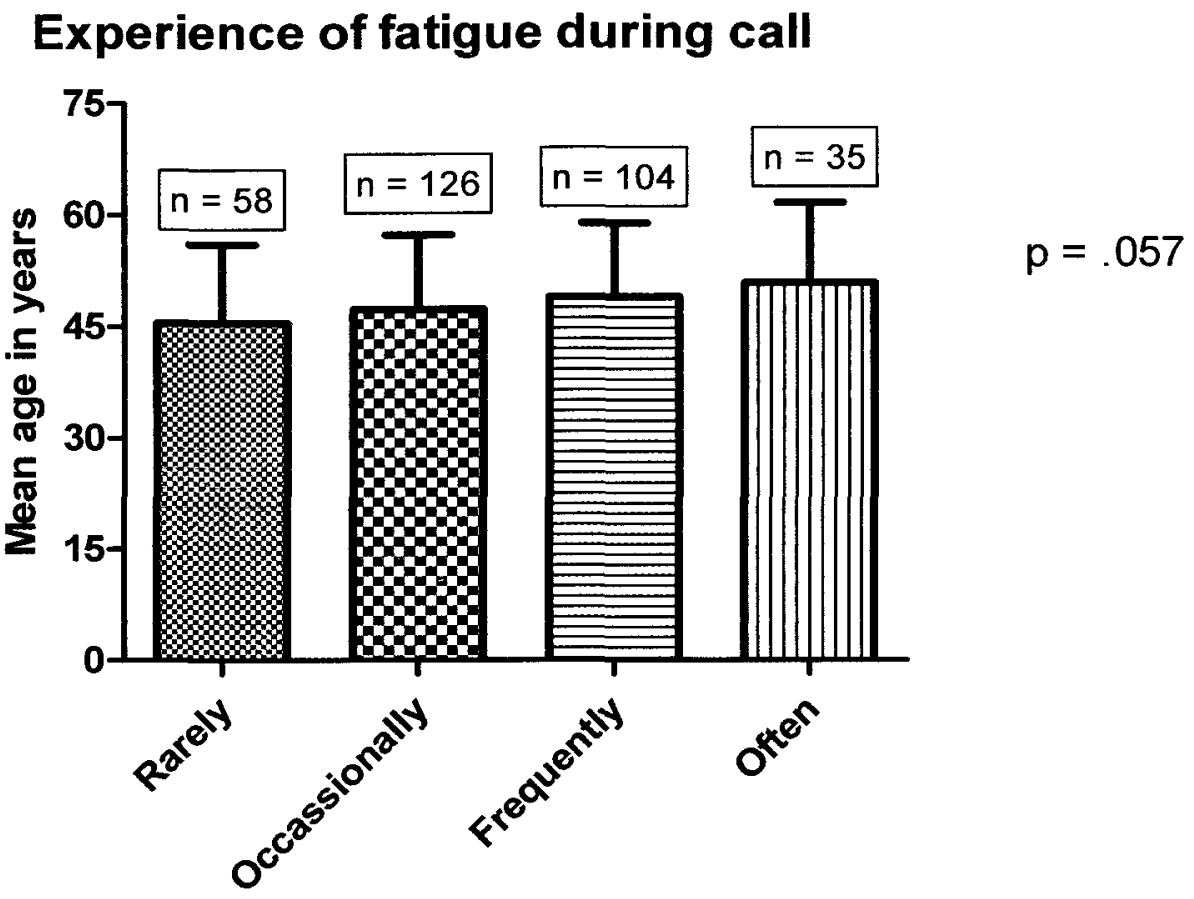

* Mean age in years compared to experience of fatigue experience during call.

Chi-square analyses were used to compare participants meeting criteria for rare fatigue (0) or frequent fatigue (1) on categorical variables of duration of call (weekday or weekend), call days per month, anesthesia days per week, physiologic and psychological symptoms, use and number of FASs or CMs, gender. (Table 6).

For call duration, $53.4 \%$ of CRNAs reported frequent fatigue for call shifts greater than 17 hours as compared to $34.5 \%$ who worked $\leq 16$ hours and $49.0 \%$ of CRNAs reported frequent fatigue for weekend shifts greater than 17 hours as compared to $26.3 \%$ 
who worked $\leq 16$ hours. More than half $(57.6 \%)$ of CRNAs reported frequent fatigue when administering anesthesia $\geq 5$ days, as compared to $42.4 \%$ who reported working $\leq 4$ days. Substantially more CRNAs who reported frequent fatigue experienced the occurrence of physiologic and psychological symptoms $51.2 \%$ and used countermeasures $(45.9 \%, n=129)$ than those who rarely experienced fatigue $(17.2 \%, n=11), 23.1 \%(n=$ 9), respectively. For the number of fatigue CMs used, $65.6 \%$ of CRNAs who reported frequent fatigue used $\geq 3 \mathrm{CMs}$ compared to 37.8 of those who reported rare fatigue.

Fifty-three percent $(n=132)$ of CRNAs reporting rare fatigue use FAS compared to $47 \%(n=117)$ of those reporting frequent fatigue. Of the 91 who reported patient care error, $57(62.6 \%)$ reported experiencing frequent fatigue. 
Table 6

Cross Tabulation for Fatigue Experience and Predictor Variables

\begin{tabular}{|c|c|c|c|c|}
\hline \multicolumn{5}{|c|}{ Fatigue Experience } \\
\hline Predictor variables & $\begin{array}{l}\text { Rare } \\
\mathrm{n}(\%)\end{array}$ & $\begin{array}{l}\text { Frequent } \\
\text { n }(\%)\end{array}$ & $\mathrm{X}^{2}(d f)$ & $p$ \\
\hline $\begin{array}{l}\text { Call Duration } \\
\qquad \begin{aligned} \text { Weekday } & \leq 16 \text { hours } \\
& >17 \text { hours }\end{aligned}\end{array}$ & $\begin{array}{r}114(65.1 \%) \\
69(46.6 \%)\end{array}$ & $\begin{array}{l}60(34.5 \%) \\
79(53.4 \%)\end{array}$ & $11.63(1)$ & .001 \\
\hline Weekend $\begin{aligned} & \leq 16 \text { hour } \\
& >17 \text { hours }\end{aligned}$ & $\begin{array}{r}59(73.8 \%) \\
123(50.8 \%) \\
\end{array}$ & $\begin{array}{r}21(26.3 \%) \\
118(49.0 \%) \\
\end{array}$ & $12.62(1)$ & .000 \\
\hline $\begin{array}{l}\text { Anesthesia days per week plus } \\
\text { call } \\
\qquad \begin{array}{l}\leq 4 \\
5 \\
\geq 6\end{array}\end{array}$ & $\begin{array}{r}87(47.5 \%) \\
83(45.4 \%) \\
13(7.1 \%) \\
\end{array}$ & $\begin{array}{l}59(42.4 \%) \\
56(40.3 \%) \\
24(17.3 \%) \\
\end{array}$ & $8.02(2)$ & .018 \\
\hline $\begin{array}{l}\text { Number of calls/month } \\
0-4 \\
5-8 \\
\geq 9\end{array}$ & $\begin{array}{r}107(64.5 \%) \\
54(50.5 \%) \\
22(44.9 \%)\end{array}$ & $\begin{array}{l}59(35.5 \%) \\
53(49.5 \%) \\
27(55.1 \%)\end{array}$ & $8.54(2)$ & .01 \\
\hline $\begin{array}{c}\text { Physio / psych symptoms } \\
\text { Yes }\end{array}$ & $105(48.8 \%)$ & $110(51.2 \%)$ & $23.18(1)$ & .000 \\
\hline $\begin{array}{l}\text { Fatigue avoidance strategies } \\
\text { Yes } \\
\text { Number of FASs } \\
0-2 \\
\geq 3 \\
\end{array}$ & $\begin{array}{l}132(53.0 \%) \\
166(57.8 \%) \\
121(42.2 \%)\end{array}$ & $117(47.0 \%)$ & $6.42(1)$ & .01 \\
\hline $\begin{array}{c}\text { Countermeasures }(\mathrm{CM}) \\
\text { Yes } \\
\text { Number of CMs } \\
0-2 \\
\geq 3\end{array}$ & $\begin{array}{r}9(23.1 \%) \\
161(62.2 \%) \\
98(37.8 \%)\end{array}$ & $129(45.9 \%)$ & $7.27(1)$ & .007 \\
\hline
\end{tabular}


Aim 3. To explore factors related to the odds of experiencing fatigue during call.

Question 3. Are there predictor related to the risk for experiencing fatigue during call?

An exploratory simultaneous logistic regression was performed to identify predictors of frequent fatigue. The model included call duration (weekday, weekend), anesthesia days per week, number of call days per month, occurrence of physiological or psychological symptoms, use of FASs, CMs, and age. Each independent ordinal and categorical variable was entered as recommended by Kraemer and Blasey (2004).

Collinearity statistics revealed VIF values $<4$ and tolerance well above 0.2 . Regression results indicate the overall model of eight predictors was statistically reliable in distinguishing of status of fatigue experience $(-2 \log$ Likelihood $=385.08$; Goodness of Fit $\left.=3.59 ; \chi^{2}(10)=49.06, p=.000\right)$. The model correctly classified $67.2 \%$ of the cases. Four predictor variables were significantly related to the likelihood of experiencing frequent fatigue. Regression coefficients are presented in Table 7. Wald statistics indicate weekend call duration, Fatigue avoidance strategy use, number of fatigue countermeasures used, and number of anesthesia days per week significant in predicting fatigue status. Certified Registered Nurse Anesthetists who report frequent fatigue are two times more likely to work a weekend shift $\geq 17$ hours_(95\% CI [1.03, 3.93], $\mathrm{p}<.041)$, use a FAS (95\% CI [1.06, 4.01], $\mathrm{p}<.033)$, use 3 or more fatigue CMs $(95 \% \mathrm{CI}[1.30,4.56], \mathrm{p}<.006)$, and work more than 6 anesthesia days per week (OR $.411,95 \%$ CI $[.180, .937], \mathrm{p}<.035)$. 
Table 7

\section{Regression Coefficients}

\begin{tabular}{|c|c|c|c|c|c|c|c|}
\hline \multirow[t]{2}{*}{ Predictor } & \multirow[t]{2}{*}{$B$} & \multirow[t]{2}{*}{ Wald } & \multirow[t]{2}{*}{$D f$} & \multirow[t]{2}{*}{$\begin{array}{l}\text { Odds } \\
\text { Ratio }\end{array}$} & \multicolumn{2}{|c|}{$\begin{array}{l}95 \% \text { Confidence } \\
\text { Interval }\end{array}$} & \multirow[t]{2}{*}{$P$} \\
\hline & & & & & Lower & Upper & \\
\hline $\begin{array}{l}\text { Duration of call } \\
\text { Weekday } \\
\text { Weekend } \\
\end{array}$ & $\begin{array}{l}.400 \\
.699\end{array}$ & 2.104 .17 & $\begin{array}{l}1 \\
1\end{array}$ & $\begin{array}{l}1.49 \\
2.01\end{array}$ & $\begin{array}{l}.868 \\
1.03\end{array}$ & $\begin{array}{l}2.56 \\
3.93\end{array}$ & $\begin{array}{l}.148 \\
.041\end{array}$ \\
\hline $\begin{array}{l}\text { Fatigue Avoidance Strategy } \\
\text { Prior to call }\end{array}$ & .723 & 4.53 & 1 & 2.06 & 1.06 & 4.01 & .033 \\
\hline $\begin{array}{l}\text { Fatigue Countermeasure } \\
\text { During call } \\
\text { \# reported used }\end{array}$ & $\begin{array}{l}.641 \\
.889\end{array}$ & $\begin{array}{l}1.99 \\
7.68\end{array}$ & $\begin{array}{l}1 \\
1\end{array}$ & $\begin{array}{l}1.90 \\
2.43\end{array}$ & $\begin{array}{l}.780 \\
1.30\end{array}$ & $\begin{array}{l}4.63 \\
4.56\end{array}$ & $\begin{array}{l}.158 \\
.006\end{array}$ \\
\hline $\begin{array}{l}\text { Days of anesthesia per week } \\
\text { including call } \\
\leq 4 \text { days per week } \\
5 \text { days per week } \\
\geq 6 \text { days per week }\end{array}$ & $\begin{array}{l}-.713 \\
-.889\end{array}$ & $\begin{array}{l}4.47 \\
2.72 \\
4.47\end{array}$ & $\begin{array}{l}2 \\
1 \\
1\end{array}$ & $\begin{array}{l}.490 \\
.411 \\
\end{array}$ & $\begin{array}{l}.210 \\
.180\end{array}$ & $\begin{array}{l}1.14 \\
.937\end{array}$ & $\begin{array}{l}.107 \\
.099 \\
.035\end{array}$ \\
\hline $\begin{array}{l}\text { Number of call days per month } \\
0-4 \text { calls per month } \\
5-8 \text { calls per month } \\
\geq 9 \text { days per month }\end{array}$ & $\begin{array}{l}-.323 \\
-.065\end{array}$ & $\begin{array}{l}1.07 \\
.689 \\
.029 \\
\end{array}$ & $\begin{array}{l}2 \\
1 \\
1\end{array}$ & $\begin{array}{l}.724 \\
.937 \\
\end{array}$ & $\begin{array}{l}.337 \\
.443\end{array}$ & $\begin{array}{l}1.55 \\
1.98\end{array}$ & $\begin{array}{l}.586 \\
.406 \\
.865 \\
\end{array}$ \\
\hline Age & .022 & 3.010 & 1 & 1.02 & .997 & 1.05 & .083 \\
\hline
\end{tabular}




\section{CHAPTER 5}

\section{DISCUSSION OF FINDINGS}

\section{Introduction}

The purpose of this descriptive study was to examine whether Certified Registered Nurse Anesthetists (CRNAs) experience fatigue during call and to assess their use of fatigue avoidance strategies (practices that prevent fatigue) and fatigue countermeasures (practices that decrease fatigue) to mitigate its effects. Study data were collected, November through December 2010, from practicing CRNA members of the American Association of Nurse Anesthetists (AANA) throughout the United States. In this chapter the research design and method, data analysis, and overall results are summarized in the context of the literature review and the theoretical model.

Implications for nursing practice, education, research, and policy are presented.

\section{Fatigue Experience}

Extended wakefulness leads to subjective sleepiness and decreases in performance and alertness (Banks \& Dinges, 2007; Barger, 2009; Philip et al, 2006). A sleep debt, a result of sleep loss, has been shown to cause a decrease in attention, cognitive performance, executive attention, vigilance and working memory, which can result in cognitive deficiencies not recognized by the affected individual (Banks $\&$ 
Dinges, 2007; Goel et al., 2009). In two separate studies (Lockley et al., 2004; Landrigan et al., 2004), sleep deprived medical residents demonstrated a decrease in neurobehavioral functions and clinical performance. In New Zealand, 23\% of staff anesthesiologists who filed an incident report indicating fatigue was a factor, was deprived two hours less sleep than their baseline, having been on-call the night prior (Gander et al., 2008). Shift-length studies of medical trainees and staff hospital nurses support growing evidence that fatigue's effect on physiological and behavioral performance influences medical error and personal injury (needle sticks, motor vehicle crashes, etc.). Evidence is lacking as to whether CRNAs who work call shifts, are fatigued. The study reported here provides initial evidence of the experience of fatigue among a sample of CRNAs.

Coding Fatigue Interventions Using the Theoretical Framework. The middlerange theory of unpleasant symptoms (Lenz et al., 1997) was selected as the theoretical foundation for this investigation as it provides a conceptual pathway for fatigue influences: physiologic, psychological, and situational factors, which can promote the occurrence of health symptoms and affect performance. Using an open-ended questionnaire, participants were asked to describe the order and frequencies of any fatigue avoidance strategies (FASs) and/or fatigue countermeasures (CMs) they used. The FASs and fatigue CMs were coded using the most suitable factor and constant comparison. Seven themes emerged from the three fatigue-associated factor groups. The physiological factor group had three themes which influenced the effect of fatigue: 'fatigue prevention' (tactics like sleeping longer the day of call, napping before call, etc.); 
'nutritional influences' such as eating small meals, or drinking caffeine; and 'exercise'. The psychological factor group was comprised of FASs or fatigue CMs of 'stress reduction', such as using deep breathing, finding a place to relax, and focusing on the job. Last, the situational factor group included two themes; actions labeled to 'decrease the occurrence of fatigue', (i.e., delegating work and taking a break), and actions to 'keep busy' (reading, talking with others or phoning someone). In both the FAS and fatigue CM questions, there were CRNAs who answered 'not applicable' or 'does not apply' as they are not called in often, or do not experience fatigue during call; others commented 'nothing works'.

In this study, CRNA anesthesia performance may be affected by fatigue related to physiologic influences of the circadian rhythm, shift length, number of hours awake, and the number of days worked per week. Indeed, over two thirds $(67 \%, \mathrm{n}=217)$ of CRNAs who used a FAS used 'fatigue prevention', for example sleeping earlier the night prior to call or napping prior to call as their chief strategy. The primary fatigue CM used by $46 \%$ of this cohort was 'nutrition' (i.e. snacks, caffeine, etc.), also grouped under the physiologic domain. These interventions are supportive of trying to 'counteract' the overwhelming physiological influence of the need for sleep. A few psychological influences that may contribute to CRNA fatigue is stress that may be associated with work demand, patient acuity, and a CRNA's coping mechanisms. In a small proportion of respondents, psychological FASs and CMs were the prime tactics ( $2 \%$ and $1 \%$ respectively). Finally, the third factor of the conceptual model is situational influences, such as demands of the call shift (long or multiple cases, ability to take a break, etc.), and 
professional obligations (having to work the next day and shift length). Situational CM tactics (keeping busy, using bright light or face washing), were the second largest domain listed after nutrition $(24 \%, n=78)$.

The framework established a foundation for respondents' answers and highlighted the interrelationship of physiology, psychology, and situational factors which could ultimately affect performance. Two thirds (67\%) of CRNAs expressed they experienced physiological or psychological symptoms when fatigued, and $28 \%$ conveyed they committed an error in patient care because of being fatigued. The framework also suggests a preceding health symptom (i.e. headache), may result in onset of other symptoms; as expressed in a few CRNA descriptions: 'mentally drained and physically tired', 'lethargy, irritable, and crankiness', and 'headache, muscle tightness, and (having) less patience'.

Interpretations of the Results. Although there is no central database to compare call shift lengths in this sample against the population, prior studies of medical residents and hospital staff nurses showed an increased risk of patient error and needle stick injuries when working shifts greater than 12 hours (Ayas et al., 2006; Landrigan et al., 2004; Scott et al., 2006; Trinkoff et al., 2007). Residents made 36\% more serious medical errors and experienced $61 \%$ more needle sticks while nurses encountered decreased vigilance, a twofold chance of a patient care error, and significantly increased risk of a needle stick injury. Almost half (46\%), of CRNAs in the study worked greater than 17 hours during a weekday call, and nearly three fourths worked greater than 17 hours during a weekend call shift (38\% reported shifts between 17 and 24 hours and 
$36.5 \%$ reported shifts greater than 25 hours). The reported patient error rate related to fatigue was $28.2 \%$. The question allowed for an open-ended response; nearly half of the occurrences were medication errors and omissions in charting. The study's error report rate was similar to the incident report rate of on-call New Zealand anesthesiologists over a two-week work period, which was $23 \%$ (Gander et al., 2008). In another call shift study, Rothschild and colleagues (2009) reported a significantly higher surgical complication rate $(6.2 \%)$ if a surgeon received less than a six-hour sleep opportunity while being on call the night prior (compared to their control cases, 3.2\%). Based upon answers in the study reported here, it is estimated $10 \%$ of CRNAs in this sample work the day after call.

A second finding in this study is the types of FASs and CMs used. Scott et al. (2010a) discovered that there were no high-risk industry fatigue-prevention programs applicable to healthcare settings; although there are a few field studies that support that work shift fatigue can be relieved by naps (Caldwell et al., 2009; Guilleminault \& Ramar, 2006). In particular, combining two interventions (a nap with caffeine or bright light) was more effective than just naps alone (Hayashi et al., 2003; Schweitzer et al., 2006). A majority of CRNAs in this study $(n=203)$ used two FASs, $60 \%$ used FASs both grouped under fatigue prevention (such as sleeping longer the night before call and napping before starting call). Of those who used two fatigue CMs $(n=188)$, the majority $(43 \%)$ used situational tactics (keeping busy, interacting with others, etc.) and alternatively, 29\% used the physiologic domain of nutrition (caffeine, snacking, etc.). See Chapter 4 , Tables 4 and 5 . 
One hundred sixteen participants in this study reported using three to four FASs, previously adopted by the aviation community (Caldwell et al., 2009) and those recommended by a lead fatigue nurse researcher (Scott et al., 2010b). Certified Registered Nurse Anesthetists FASs parallel those reported in previous research: a) healthy sleep practices, such as getting at least eight hours of sleep and being well-rested before starting call; b) avoiding alcohol and caffeine before bed; c) establishment of a sleep routine, supported by statements such as 'practicing sleep hygiene'; and d) napping before call. One hundred twenty four CRNAs reported using three to four CMs, also congruent with Caldwell and Scott's recommendations of naps, activity breaks, (walking, social interaction), workspace lighting, and the need for adequate staffing to allow breaks and naps.

A third finding of this study was comparing criteria for rare or frequent fatigue. Those who experienced more frequent fatigue worked longer weekday and weekend shifts (each greater than 17 hours), worked five or more days per week doing anesthesia, experienced the occurrence of physiological or psychological symptoms, and used a fatigue $\mathrm{CM}$. Those reporting rare fatigue used a FAS and reported using zero to two CMs. Although CRNAs who used more fatigue CMs reported fatigue more frequently (65.6\% compared to $37.8 \%$ ), the use of more CMs is likely the result of fatigue, not the cause of it.

An exploratory regression analysis indicated that four predictor variables were significantly associated with the likelihood of experiencing frequent fatigue. Participants who reported frequent fatigue were two times more likely to work a weekend shift greater 
than 17 hours, use a fatigue avoidance strategy, use three or more fatigue CMs, and work six or more anesthesia days per week. See Chapter 4, Table 7. It is unclear whether CRNAs employ FASs and a higher number of CMs knowing they may experience fatigue, or practice interventions having experienced fatigue during past call shifts. The work shift variables reflect a similar study by Trinkoff and colleagues (2007) who examined the association between work conditions (working fast, concentrating for long periods, and physical demands), work schedule, and needle stick injury in 2,624 nurses. In Trinkoff's study, regression analysis (work schedule with age adjusted), revealed work variables (hours worked per day, weekends, non-day shift, and shifts greater than 13hours), were significantly associated with occurrence of needle stick injuries in the past year. Although this study did not explore CRNA injury, Trinkoff's study suggests fatigue related to work variables may have been a factor in the nurse's injury rate.

Finally, of 91 CRNAs who reported a patient care error related to fatigue, 57 $(62.6 \%)$ reported experiencing frequent fatigue. Fatigue was also reported in healthcare provider injury and patient errors in the next two studies described. In 2006, Ayas and colleagues analyzed 192 intern diary logs over a 28-day study and discovered two of the most reported contributing factors of increased needle stick injuries were a lapse in concentration and fatigue (64\% and $31 \%$ respectively). West (2009) attempted to observe resident distress, versus fatigue, as a contributor to a self-perceived major medical error. Residents reporting at least one error had lower quality of life scores, higher burnout rates, and a greater fatigue score (difference, $0.54 ; \mathrm{p}=.006$ ). 
When age as a continuous variable was explored, there was a significant mean age difference by $C R N A s$ experiencing rare fatigue $(\mathrm{M}=46.72, \mathrm{SD}=10.25)$ and frequent fatigue $(M=49.37, \mathrm{SD} 10.12), \mathrm{p}=.02$. This is not supported by recent work of Biddle and Acker (2011), who surveyed a random sample of CRNAs to discover their sleep habits and impact on the profession. They found no relationship between advancing age and reported sleep-related issues, although perhaps these comparisons are not identical. The authors stated nearly $16 \%$ of respondents reported falling asleep while providing an anesthetic, even when using fatigue CMs (walking, interacting with others, and asking for a break), while half (49\%), observed a colleague in a sleep-related behavior. Biddle and Aker mention scheduling traditions and the 24-hour call shift should be discussed amongst the profession. They also reported $25 \%$ of CRNA respondents used a pharmacologic aid to achieve or maintain sleep. Their study may indicate that one fourth of CRNAs used a pharmacological aid to alter physiological and / or psychological processes to prevent the experience of fatigue and other health symptoms (sleepiness, anxiety, headache, etc.), ultimately affecting their work performance. Notably, a review of literature in 2008 (AANA/Council, 2008) condensed evidence of four conclusive studies and summarized that patient care errors are related to shift length; the article ended with a bold statement "Fatigue can induce a state in anesthesia providers that will cause more medical errors".

Implications for Practice and Education. This study provides preliminary evidence of variables associated with the experience of frequent fatigue, which may influence the onset of health symptoms and affect patient care: working call shifts greater 
than 17 hours on a weekend and working six or more days per week, even with the use of FASs and fatigue CMs. This study provides initial findings to add to the scientific knowledge about fatigue in advanced practice nurses and the hours of a call shift (versus scheduled shifts). Recommendations by lead authorities in healthcare worker fatigue (Caldwell et al., 2009; Rosekind, 2005; Scott et al., 2010b) support use of FASs (healthy sleep practices, napping before a shift, etc.), and fatigue CMs (naps, breaks, bright lights, and interacting with others), as well as policies aimed at limiting consecutive calls and time off between work shifts. Educating CRNAs on these strategies is recommended, although Woodward and colleagues (2010) argue this strategy affords the lowest level of error reduction. Notwithstanding, information is often the first step in behavior change.

Findings of this study are somewhat perceptive, the longer a person's call shift or the more days per week worked, the greater the chance of fatigue. Previously, there was no evidence whether CRNAs working call shifts experience fatigue; even though recently Biddle and Acker (2011) provide data on several sleep-related behaviors. The challenge remains that the concept of fatigue itself is a multidimensional, subjective phenomenon (Fitzpatrick \& Wallace, 2006) and an individual's response to fatigue vary significantly (Van Dongen et al., 2004). Medical competence and institutional processes may contribute to an individual's actions while on call, and may not have any relationship to fatigue. Many elements that contribute to fatigue, or are the result of it, may not have been captured in this study. However, there were positive and significant associations between several of the variables explored.

This study presents findings related to the experience of fatigue and provides 
substantive knowledge to administrators, challenges the individual practitioner to be aware of fatigue's effect on performance, and supports a relationship between healthcare worker fatigue and patient error. Call shift fatigue is indeed a concern to this CRNA cohort and a majority use fatigue interventions to mitigate its effects. Indeed, findings from this study indicate increased frequency of fatigue experience if one does not use a FAS or when using more than three CMs. Some of the study findings may benefit other healthcare workers.

Limitations. There are several limitations to this study. First, the internet survey formatting structure, some multi-column, multiple-choice questions separated into two single questions, may have caused confusion and influenced participant response. Second, the sample consisted only of AANA members, albeit a small sampling, limiting generalizability of the $10 \%$ who are not members. Finally, additional variables for example number of years of practice, volume, and acuity of patient load, may have provided important information. Regardless of these limitations, this study has provided important information on CRNAs experience of fatigue and associated factors not previously studied.

Recommendations for Research. This is the first study the investigator knows of that has examined the phenomena of fatigue experience and the use of fatigue avoidance and countermeasures among a national sample of CRNAs. The respondents for this study reflect only a small number of CRNAs; a larger group of CRNAs needs to be surveyed to support these initial findings. Several additional areas should also be examined including CRNA injury (i.e. needle sticks, drowsy driving), types of patient error, and near misses. 
Indeed, the efficacy of FASs and CMs that are most effective should be identified. Third, an investigation to include other physiologic, psychological, or situational variables that affect performance is suggested, as well as biological and behavioral markers of fatigue (if available and able to be isolated). Finally, fatigue awareness and education programs to promote healthy sleep and alertness should be developed, implemented, and evaluated.

Policy and Conclusions. Biddle and Alder (2011) provide outcomes from the first national data on CRNAs sleep practices; based upon their results they argue for dialogue between policy makers, clinicians, and researchers. Although a causal effect of healthcare worker fatigue and medical error has not been established, other industries have strict rules and safeguards to govern overtime and shift length to prevent errors and accidents. It is without question, irresponsible of any professional in a high-risk industry not to adhere to professional and ethical guidelines to prevent fatigue, and to be aware of strategies to mitigate its influence. According to the AANA website (AANA, 2011) CRNAs in some states are the sole providers in nearly 100 percent of rural hospitals and based upon staffing patterns limiting call work hours may not be an achievable solution. Woodward and associates (2010), suggest the highest level for error reduction strategy is to use procedures which make the occurrence of an error difficult. In the context of patient safety, nurses, as the largest professional body in healthcare (Bureau of Labor Statistics, 2008) can and should influence policy and advocate for safe working limits while recognizing the limitations of agencies requiring 24 hour services. 
REFERENCES

American Association of Nurse Anesthetists. (2010). Who We Are. Retrieved from http://www.aana.com/AboutAANA.aspx?id=38\&linkidentifier=id\&itemid=38 American Association of Nurse Anesthetists. (2011). Certified Registered Nurse Anesthetists (CRNAs) at a Glance. Retrieved from http://www.aana.com/ataglance.aspx.

American Association of Nurse Anesthetists / Council for Public Interest in Anesthesia. (2008). Fatigued anesthesia providers make errors. Quality Review in Anesthesia. 11(3), 2-3.

Accreditation Council for Graduate Medical Education. (2007). Common program requirements. Retrieved from http://www.acgme.org/acWebsite/dutyHours/dh_ComProgrRequirmentsDutyHours0 707.pdf

Accreditation Council for Graduate Medical Education. (2011). ACGME Duty Hours Standards Fact Sheet. Retrieved from http://www.acgme.org/acWebsite/newsRoom/ACGMEdutyHoursfactsheet.pdf Alreck, P. L., \& Settle, R. B. (1995). The survey research handbook $\left(2^{\text {nd }}\right.$ ed. $)$. Boston, MA. Irwin Professional Publishing.

Ayas, N. T., Barger, L. K., Cade, B. E., Hashimoto, D. M., Rosner, B., Cronin, J. W., et al. (2006). Extended work duration and the risk of self-reported percutaneous injuries in interns. JAMA, 296(9), 1055-1062. 
Banks, S., \& Dinges, D. F. (2007). Behavioral and physiological consequences of sleep restriction. Journal of Clinical Sleep Medicine 3, 519-528.

Baranski, L. (2007). Fatigue, sleep loss, and confidence in judgment. Journal of Experimental Psychology, 13(4), 182.

Barger, L. K., Lockley, S. W., Rajaratnam, S. M., \& Landrigan, C. P. (2009).

Neurobehavioral, health, and safety consequences associated with shift work in safety-sensitive professions. Current Neurology \& Neuroscience Reports, 9(2), 155164.

Berlin, L. (2008). Liability of the sleep-deprived resident. American Journal of Roentgenology, 190(4), 845-851. doi:10.2214/AJR.07.3311

Biddle, C., \& Aker, J., (2011). The national study of sleep-related behaviors of nurse anesthetists: personal and professional implications. AANA Journal 79(4), 324-31.

Bureau of Labor Statistics (2008). Career guide to industries. Retrieved from http://www.bls.gov/oco/cg/cgs035.htm\#related

Burns, N., Grove, S. K. (2001). The Practice of Nursing Research (4th ed.). Philadelphia, PA: W.B. Saunders Company.

Caldwell, J. A., Mallis, M. M., Caldwell, J. L., Paul, M. A., Miller, J. C., Neri, D. F., et al. (2009). Fatigue countermeasures in aviation. Aviation Space \& Environmental Medicine, 80(1), 29-59.

Cannon-Diehl, M. R. (2009). Simulation in healthcare and nursing: State of the science. Critical Care Nursing Quarterly.32, 128-136. 
Carskadon, M. A., Dement, W. C., Mitler, M. M., Roth, T., Westbrook, P. R., \& Keenan, S. (1986). Guidelines for the multiple sleep latency test (MSLT): A standard measure of sleepiness. Sleep, 9(4), 519-524.

Creswell, J. W., (2009). Research design: qualitative, quantitative, and mixed methods approaches. ( $3^{\text {rd }}$ ed.). Thousand Oaks, CA: Sage Publications, Inc.

Demidenko, E. (2007). Sample size determination for logistic regression revisited. Statistics in medicine, 26, 3385-97.

Diekelmann S., \& Born, J., (2010). The memory function of sleep. Nature.com 11, 11421.

Doran, S. M., Van Dongen, H. P., \& Dinges, D. F. (2001). Sustained attention performance during sleep deprivation: Evidence of state instability. Archives Italiennes De Biologie, 139(3), 253-267.

Eastridge, B. J., Hamilton, E. C., O'Keefe, G. E., Rege, R. V., Valentine, R. J., Jones, D. J., et al. (2003). Effect of sleep deprivation on the performance of simulated laparoscopic surgical skill. American Journal of Surgery, 186(2), 169-174.

Ekstedt, M. B. N. S., Akerstedt, T., \& Soderstrom, M. (2004). Microarousals during sleep are associated with increased levels of lipids, cortisol, and blood pressure. Psychosomatic Medicine, 66(6), 925-931.

Fitzpatrick, J.J., Wallace, K. (Ed.). (2006). Encyclopedia of nursing research (2nd ed.). New York: Springer.

Gaba, D. M. (2007). The future vision of simulation in healthcare. Simulation in Healthcare. 2, 126-135. 
Gander, P., Millar, M., Webster, C., \& Merry, A. (2008). Sleep loss and performance of anaesthesia trainees and specialists. Chronobiology International, 25(6), 1077-1091.

Goel, N., Rao, H., Durmer, J. S., \& Dinges, D. F. (2009). Neurocognitive consequences of sleep deprivation. Seminars in neurology. 29, 320-339.

Grantcharov, T. P., Bardram, L., Funch-Jensen, P., \& Rosenberg, J. (2001). Laparoscopic performance after one night on call in a surgical department: Prospective study. BMJ, 323(7323), 1222-1223.

Guilleminault, C. B., \& Ramar, K. (2006). Naps and drugs to combat fatigue and sleepiness. Annals of Internal Medicine, 144, 856-857.

Hayashi, M., Masuda, A., \& Hori, T. (2003). The alerting effects of caffeine, bright light and face washing after a short daytime nap. Clinical Neurophysiology.114, 22682278 .

Howard, S. K., Gaba, D. M., Smith, B. E., Weinger, M. B., Herndon, C., Keshavacharya, S., et al. (2003). Simulation study of rested versus sleep-deprived anesthesiologists. Anesthesiology, 98(6), 1345-55.

Institute of Medicine: Keeping Patients Safe: Transforming the Work Environment of Nurses. Washington, DC: National Academy Press, 2004.

Ji, Q., Lan, P., \& Looney, C. (2006). A probabilistic framework for modeling and realtime monitoring human fatigue. Journal of IEEE Transactions on Systems, Man and Cybernetics, 36(5), 862-75.

Johns, M. W. (1991). A new method for measuring daytime sleepiness: the Epworth Sleepiness Scale. Sleep, 14, 540-45. 
Jordan, L. M., Kremer, M., Crawforth, K., \& Shott, S. (2001). Data-driven practice improvement: The AANA foundation closed malpractice claims study. AANA Journal, 69(4), 301-311.

Kabes, A. M., Knop Dumstorff, J., Wosje, M. (2010). Sleep and Vigilance in the Student Registered Nurse Anesthetist: A Descriptive Study [thesis]. Sioux Falls, SD: Mount Marty College.

Katz, M. H., (1999). Multivariable analysis: A practical guide for clinicians. Cambridge University Press, University of California, San Francisco.

Kayumov, L., Zhdanova, I. V., \& Shapiro, C. M. (2000). Melatonin, sleep, and circadian rhythm disorders. Seminars in Clinical Neuropsychiatry, 5(1), 44-55.

Kerlinger, F. N., \& Lee, H. B. (2000). Foundations of behavioral research (4th ed.). Fort Worth, Texas: Harcourt College Publishers.

Kraemer, H. C., Blasey, C. M. (2004), Centring in regression analyses: a strategy to prevent errors in statistical inference. International Journal of Methods in Psychiatric Research, 13, 141-51.

Kohn, L., Corrigan, J. M., Donaldson, M. eds. (Ed.). (2000). To err is human: Building a safer health system. Washington, DC: National Academies Press.

Lan, P., Ji, Q., \& Looney, C. G. (2002). Information fusion with Bayesian networks for monitoring human fatigue. 1 (Proceedings of the Fifth International Conference on), 535-542.

Landrigan, C. P., Rothschild, J. M., Cronin, J. W., Kaushal, R., Burdick, E., Katz, J. T., et al. (2004). Effect of reducing interns' work hours on serious medical errors in 
intensive care units. New England Journal of Medicine, 351(18), 1838-1848.

Lee, K. A., Hicks, G., Nino-Murcia, G. (1991). Validity and reliability of a scale to assess fatigue. Psychiatry Research,36(3), 291-8.

Leff, D. R., Aggarwal, R., Rana, M., Nakhjavani, B., Purkayastha, S., Khullar, V., et al. (2008). Laparoscopic skills suffer on the first shift of sequential night shifts: Program directors beware and residents prepare. Annals of Surgery, 247(3), 530-539.

Leff, D. R., Orihuela-Espina, F., Athanasiou, T., Karimyan, V., Elwell, C., Wong, J., et al. (2010). "Circadian cortical compensation": A longitudinal study of brain function during technical and cognitive skills in acutely sleep-deprived surgical residents. Annals of Surgery, 252(6), 1082-1090. doi:10.1097/SLA.0b013e3181ff449c

Lenz, E. R., Suppe, F., Gift, A. G., Pugh, L. C., \& Milligan, R. A. (1995). Collaborative development of middle-range nursing theories: Toward a theory of unpleasant symptoms. Advances in Nursing Science, 17(3), 1-13.

Lenz, E. R., Pugh, L. C., Milligan, R. A., Gift, A., \& Suppe, F. (1997). The middle-range theory of unpleasant symptoms: An update. Advances in Nursing Science, 19, 14-27. Littner, M. R., Kushida, C., Wise, M., Davila, D. G., Morgenthaler, T., Lee-Chiong, T., et al. (2005). Practice parameters for clinical use of the multiple sleep latency test and the maintenance of wakefulness test. Sleep, 28(1), 113-121.

Lockley, S. W., Cronin, J. W., Evans, E. E., Cade, B. E., Lee, C. J., Landrigan, C. P., et al., (2004). Effect of reducing interns' weekly work hours on sleep and attentional failures. New England Journal of Medicine, 351(18), 1829-1837. 
Markwald, R. R., Lee-Chiong, T. L., Burke, T. M., Snider, J. A., \& Wright, K. P., Jr. (2010). Effects of the melatonin MT-1/MT-2 agonist ramelteon on daytime body temperature and sleep. Sleep, 33(6), 825-831.

Meadows, K. A. (2003). So you want to do research? 4: An introduction to quantitative methods. British Journal of Community Nursing, 8(11), 519-526.

Mertler, C. A. \& Vannatta, R. A. (2005). Advanced and multivariate statistical methods ( $3^{\text {rd }}$ Ed.). Los Angeles, CA: Pyrczak Publishing.

Mertler, C. A. \& Vannatta, R. A. (2010). Advanced and multivariate statistical methods (4th Ed.). Los Angeles, CA: Pyrczak Publishing.

Munro, B. H., (2005). Statistical methods for health care research. Volume 2. Philadelphia: Lippincott Williams \& Wilkins.

National Highway Traffic Safety Administration (2003). Findings: National Survey of Distracted and Drowsy Driving. Retrieved from http://www.nhtsa.gov/people/injury/drowsy_drivingl/surveydistractive03/drowsy.htm

National Sleep Foundation (2008). Sleep in America poll: Summary of findings. Retrieved from http://www.sleepfoundation.org/sites/default/files/2008\%20POLL\%20SOF.PDF Owens, J. A. (2001). Sleep loss and fatigue in medical training. Current Opinion in Pulmonary Medicine, 7(6), 411-418. 
Parthasarathy, S., Hettiger, K. R. P. S. G. T., Budhiraja, R., \& Sullivan, B. (2007). Sleep and well-being of ICU housestaff. Chest, 131(6), 1685-1693. doi:10.1378/chest.061398

Philip, P., Taillard, J., Moore, N., Delord, S., Valtat, C., Sagaspe, P., et al. (2006). The effects of coffee and napping on nighttime highway driving: A randomized trial. Annals of Internal Medicine, 144(11), 785-791.

Piper, B. F., Lindsey, A. M., Dodd, M. J., Ferketich, S., Paul, S. M., \& Weller, S. (1989). The development of an instrument to measure the subjective dimension of fatigue. In Funk, S. G., Tornquist, E. M., Campagne, M. T., Archer Gopp, L., \& Wiese, R.A. (eds). Key Aspects of Comfort. Management of Pain Fatigue and Nausea. New York: Springer Publishing Company.

Rogers, A. E., Hwang, W. T., Scott, L. D., Aiken, L. H., \& Dinges, D. F. (2004). The working hours of hospital staff nurses and patient safety. Health Affairs, 23(4), 202212.

Rosekind, M. R. (2005, Spring). Managing fatigue 24/7 in health care: Opportunities to improve safety. Anesthesia Patient Safety Foundation, 20, 6.

Rothschild, J. M., Keohane, C. A., Rogers, S., Gardner, R., Lipsitz, S. R., Salzberg, C. A., et al. (2009). Risks of complications by attending physicians after performing nighttime procedures. JAMA, 302(14), 1565-1572.

Rowland, L. P., \& Pedley, T. A. (Eds.). (2010). Merritt's neurology (12th ed.). Philadelphia, PA: Lippincott Williams \& Wilkins. 
Ruger, M., Gordijn, M. C., Beersma, D. G., de Vries, B., \& Daan, S. (2006). Time-ofday-dependent effects of bright light exposure on human psychophysiology: Comparison of daytime and nighttime exposure. American Journal of Physiology. Regulatory, Integrative and Comparative Physiology, 290(5), R1413-20.

Schweitzer, P. K., Randazzo, A. C., Stone, K., Erman, M., Walsh, J. K. (2006). Laboratory and field studies of naps and caffeine as practical countermeasures for sleep-wake problems associated with night work. Sleep, 29(1), 39-50.

Sheehan, K. B. (2001). E-mail survey response rates: A review. Journal of ComputerMediated Communication, 6(2), 0-0. doi:10.1111/j.1083-6101.2001.tb00117.x Scott, L. D., Hwang, W. T., \& Rogers, A. E. (2006). The impact of multiple care giving roles on fatigue, stress, and work performance among hospital staff nurses. Journal of Nursing Administration, 36(2), 86-95.

Scott, L. D., Rogers, A. E., Hwang, W. T., \& Zhang, Y. (2006). Effects of critical care nurses' work hours on vigilance and patients' safety. American Journal of Critical Care: An Official Publication, American Association of Critical-Care Nurses, 15(1), $30-37$.

Scott, L. D., Hwang, W. T., Rogers, A. E., Nysse, T., Dean, G. E., \& Dinges, D. F. (2007). The relationship between nurse work schedules, sleep duration, and drowsy driving. Sleep, 30(12), 1801-1807.

Scott, L. D., Hofmeister, N., Rogness, N., \& Rogers, A. E. (2010a). Implementing a fatigue countermeasures program for nurses: A focus group analysis. Journal of Nursing Administration, 40(5), 233-240. 
Scott, L. D., Hofmeister, N., Rogness, N., \& Rogers, A. E. (2010b). An interventional approach for patient and nurse safety: A fatigue countermeasures feasibility study. Nursing Research, 59(4), 250-258.

Schonlau, M., Fricker, R. D., \& Elliott, M. N. (2002). Conducting research surveys via E-mail and the Web. 201 North Craig Street, Pittsburgh, PA 22202 USA, RAND. Shojania, K. G., Duncan, B. W., McDonald, K. M., Wachter, R. M., \& Markowitz, A. J. (2001). Making health care safer: A critical analysis of patient safety practices. Evidence Report: Technology Assessment (Summary), (43), i-x, 1-668.

Stedman. (2005). Stedman's medical dictionary (28th ed.). Philadelphia: Lippincott Williams \& Wilkins.

Stone, P. W., Du, Y., Cowell, R., Amsterdam, N., Helfrich, T. A., Linn, R. W., et al. (2006). Comparison of nurse, system and quality patient care outcomes in 8-hour and 12-hour shifts. Medical Care, 44(12), 1099-1106.

Taillard, J., Philip, P., Coste, O., Sagaspe, P., \& Bioulac, B. (2003). The circadian and homeostatic modulation of sleep pressure during wakefulness differs between morning and evening chronotypes. Journal of Sleep Research, 12(4), 275-282.

Taillard, J., Moore, N., Claustrat, B., Coste, O., Bioulac, B., \& Philip, P. (2006). Nocturnal sustained attention during sleep deprivation can be predicted by specific periods of subjective daytime alertness in normal young humans. Journal of Sleep Research, 15(1), 41-45.

The American Nurses Association Website. (2008). Mandatory overtime. Retrieved from http://www.nursingworld.org/MainMenuCategories/ANAPolicticalPower/State/State 
LegislativeAgenda/MandatoryOvertime.aspx

Tiesinga, L. J., Dassen, T. W., \& Halfens, R. J. (1996). Fatigue: A summary of the definitions, dimensions, and indicators. Nursing Diagnosis : ND : The Official Journal of the North American Nursing Diagnosis Association, 7(2), 51-62.

Trinkoff, A. M., Le, R., Geiger-Brown, J., \& Lipscomb, J. (2007). Work schedule, needle use, and needlestick injuries among registered nurses. Infection Control \& Hospital Epidemiology, 28(2), 156-164.

Van Dongen, H. P., Baynard, M. D., Maislin, G., \& Dinges, D. F. (2004). Systematic interindividual differences in neurobehavioral impairment from sleep loss: Evidence of trait-like differential vulnerability. Sleep, 27(3), 423-433.

Van Dongen, H. P., \& Dinges, D. F. (2005). Sleep, circadian rhythms, and psychomotor vigilance. Clinics in Sports Medicine, 24(2), 237-249.

Wachter, R. M. (2009). Patient safety at ten: unmistakable progress, troubling gaps. Health Affairs, 29(1), 165-73.

West, C. P., Tan, A. D., Habermann, T. M., Sloan, J. A., \& Shanafelt, T. D. (2009). Association of resident fatigue and distress with perceived medical errors. JAMA, 302(12), 1294-1300.

Woodward, H. I., Mytton, O. T., Lemer, C., Yardley, I. E., Ellis, B. M., Rutter, P. D., et al. (2010). What have we learned about interventions to reduce medical errors? Annual Review of Public Health, 31, 479-497. 
Appendix A

Theory of Unpleasant Symptoms: An Update ${ }^{1}$

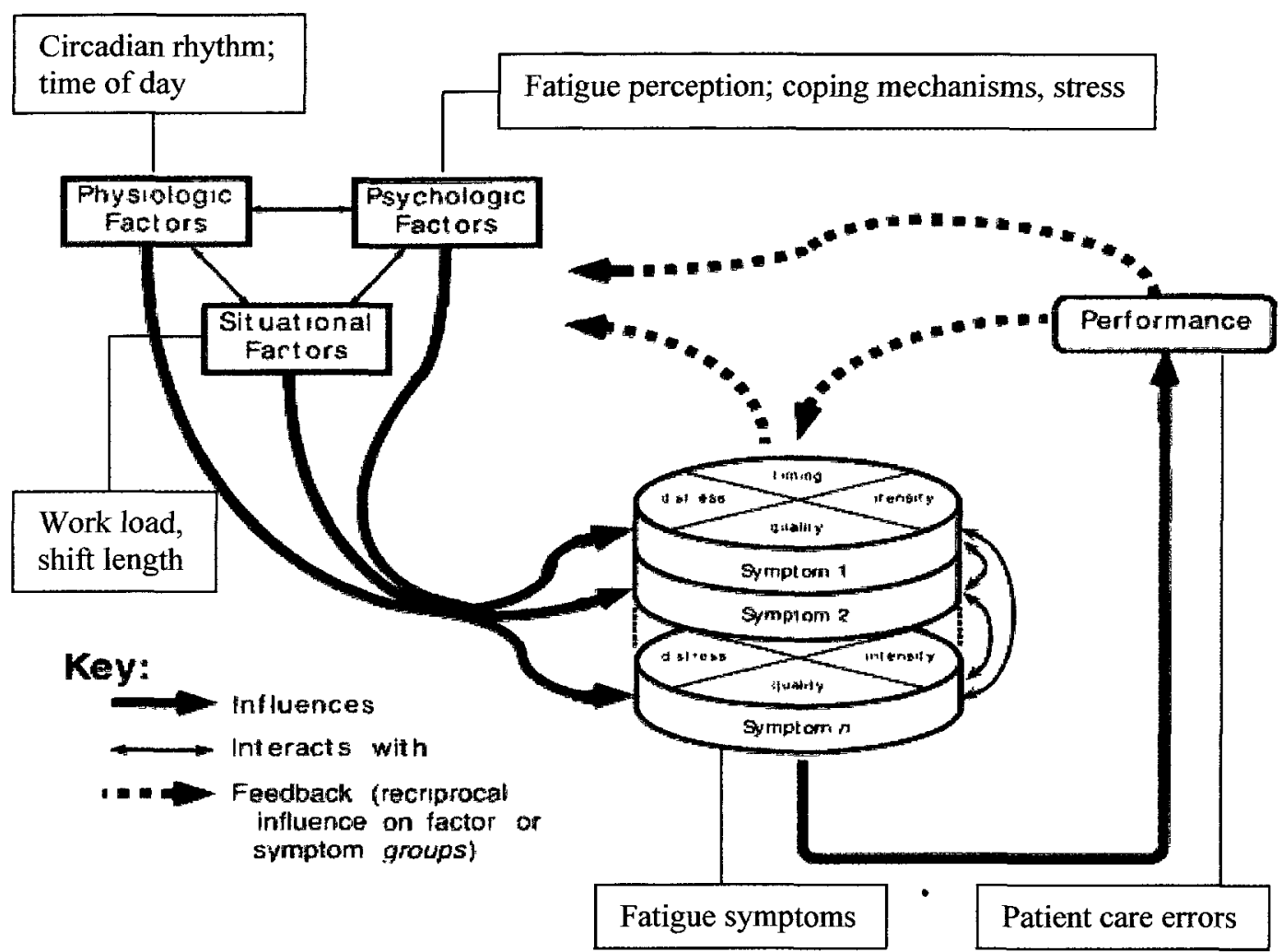

${ }^{1}$ From: The middle-range theory of unpleasant symptoms: An update, by Lenz, E. R.; Pugh, L. C., Milligan, R. A.; Gift, A., \& Suppe, F. (1997). Advances in Nursing Science 19(3), p.16. Reprinted with permission / Copyright (C) 2009 Wolters Kluwer 
Appendix C

\section{Survey Instrument - Page 1}

11/15/2010 17:21 $8475924317 \quad$ AANA
A survey of call-shift fatigue counterncasures and strategics used by Certificd Registered... Page I of 6

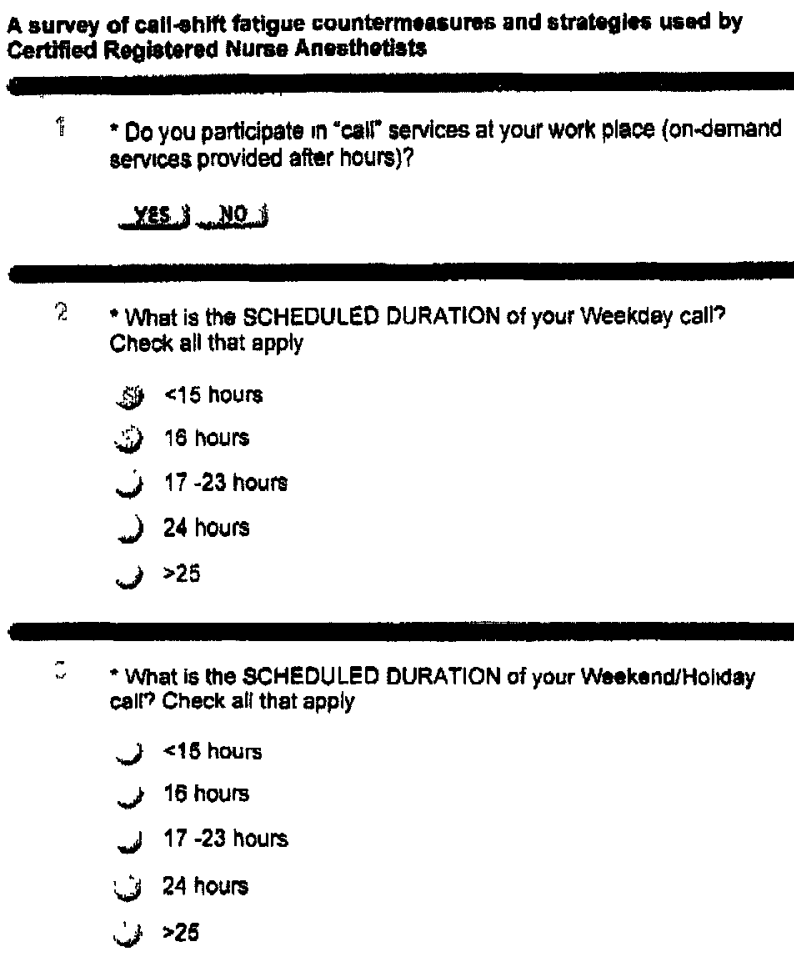

* In an average MONTH, how many calls do you have?

$3<2$

3.4

(25 6

7-8 


\section{Appendix C}

\section{Survey Instrument - Page 2}

11/15/2010 17:21 8476924317

AANA

PAGE $04 / 98$

A survcy of call-shift fatıgue countermeasures and strategtes used by Certified Registered

Page 2 of 6

\footnotetext{
"Which strategy do you think is the most effective?
}

1 - When you experience fattgue what FATIGUE COUNTERMEASURE(S) do you use to minimize the effects? Note A fatigue countermeasure is defined as an action to oppose the 


\title{
Appendix C
}

\section{Survey Instrument - Page 3}

\author{
11/15/2010 17:21 8476924317 \\ AANA \\ PAGE 05/08
}

A survey of call-shift Latigue countermeasures and strategies used by Certified Registered... Pagc 3 of 6

effects of fatigue.

In order of frequency, list the fatigue countermeasure(s) you use Describe and quantify what you do

53 . Which countermeasure do you think is the most eflectlve?

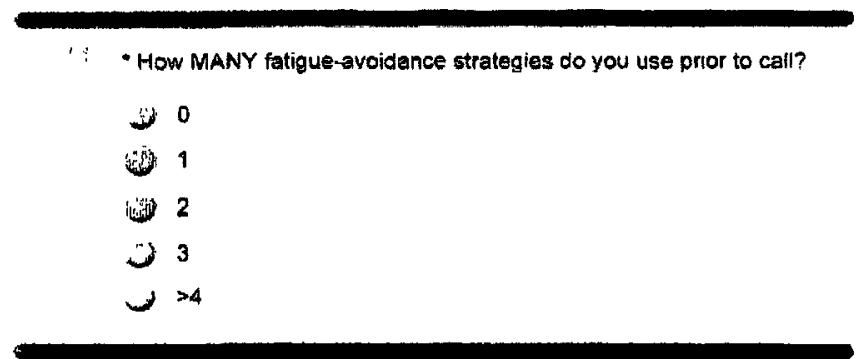

:2. How MANY fatigue countermeasures do you use during call?

0

w 1

2

3

$>4$

$1: 3$ - Prior to call, what is the AVERAGE number of consecutive hours you are awake?

\# of hours:

Wh : What is the AVERAGE number of contecutive hours you are awake AFTER starting a call shift?

\# of hours: 
Appendix C

Survey Instrument - Page 4

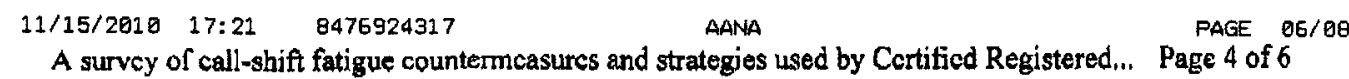

it: "Duning call, If you need to prepare for a case or procedure and feel fatigued, do you perform a fatigue countermeasure?

$\sim$ No

Depends on how sleepy or fatigued, but usually yes, countermeasura PRIOR to case

3. Depends on how sleepy of fatlgued, but usually yes,

1. countermeasure DURING case

Countermeasure performed (List countermeasure and duration

$\checkmark$ For example, drink coffee prior to case or walk around the room during the case)

16 - Have you EVER committed an orror in patient care while doing anesthesla because you were fatigued?

- Yes

- No

3 Please explain the number of occasions and what you did during the situation, if anything

- Do you feel FATIQUE is a common problem that CRNAS experience?

- Yes

(2) No

(3) Do not know

$: 5$ "How long does it take you to 'recover' from a call shift?

$\#$ of hours

is "When you experience fatigue, do you experience physical or psychological symptoms?

$\lambda$ No

- 1 Yes

$\checkmark$ Please explesin 
Appendix C

Survey Instrument - Page 5

$11 / 15 / 2910 \quad 17: 21 \quad 8476924317$

AANA

PAGE 07/08

A survcy of call-shift fatigue countermeasures and strategies used by Certified Registered... Page 5 of 6

A survey of call-shitt fatlgue countermeasures and strategies used by Certified Reglstered Nurse Anesthetists

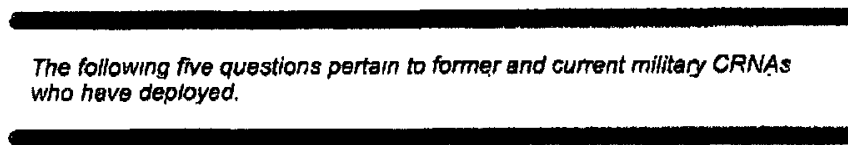

20 How many deys were you deployed?

430 days

(- $31-90$ days

$391-180$ days

$181-210$ days

$>210$ days

$2 i$ Did you feel you had adequate time for sleep in onder to pertorm your anesthesia duties safely while deployed?

$\rightarrow$ Yes

( No

3 Sometimes

2: Have you EVER committed an error in patient care, while doing anesthesia, because you were fatigued while deployed?

No

3) Yes, already explained in previous section on being fatigued

Yes, different occasion(s) than previous section on

$\checkmark$ being fatigued while on call

Please explain the number of occasions and what you did durning

$\checkmark$ the situation, if anything

23 Do you feel FATIGUE is a common pmoblem MIUTARY CRNAs experience during deployment?

- Yes

No

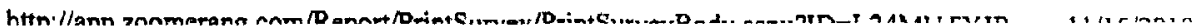




\title{
Appendix C
}

\section{Survey Instrument - Page 6}

\author{
11/15/2010 17:21 8476924317 \\ AANA \\ PAGE $08 / 88$ \\ A survey of call-shift fatigue countermcasures and strategies used by Certified Registered... Page 6 of 6
}

Do not know

\section{A survey of call-shift fatigue countermeasures and strategies used by Certifled Registered Nurse Anesthetists}

in ? What is your GENDER?

3 Female

Male

2.5. - Please list your AGE:

is is there anything you would like to add regarding CRNA or jobrelated fatigue? 
Appendix D

\title{
Cover Letter
}

\section{A survey of call-shift fatigue countermeasures and strategies used by Certified Registered Nurse Anesthetists}

\author{
Dear CRNA,
}

I am a CRNA in the Doctor of Philosophy program at the University of San Diego, Hahn School of Nursing and Health Science. I invite you to participate in this research project by filling out the attached survey. The purpose of the survey is to determine if CRNAs who participate in on-demand after-hours anesthesia work, specified as "call", use fatigue countermeasures or fatigue-avoidance strategies.

Your participation is voluntary. You may leave blank questions you do not wish to answer, or terminate the survey at any time by closing the internet page. Your participation or refusal to answer questions will not affect your AANA membership, job status, or benefits you are entitled. Your responses are confidential and data from this research will be reported in aggregate. No individual identifiers are contained on the returned survey. A third party distributes the survey and the primary investigator will not have access to the survey database. Other survey participants do not have visual access to your answers. Please do not place identifying information on the survey. The results will be provided to me as an Excel file without identifiers. The results of the survey may be presented or published in professional arenas.

Although there are no known physical risks to participation, you may conceivably become tired while completing the survey. Negative emotions of fear and sadness may occur when you are asked to recall occurrences of fatigue or for caring for patients when fatigued. If you do not wish to continue, you may terminate the survey by closing the internet page. If you experience negative emotions such as fear, anxiety or sadness, and would like to speak to someone, call the San Diego County Mental Health 24-hour Hotline at 1-800-479-3339.

If you agree to participate, please answer the survey, which should take about 12 minutes. Completion and return of the survey will be your implied consent to participate. Although you may not benefit from participating, others may ultimately benefit from knowledge obtained in this study. There is no cost to you for completing and returning the survey.

If you would like more information about this study, please contact me and/or my dissertation chairperson, Dr. Joseph Burkard. Thank you for your support in completing this project.

Sincerely,

Ramona M. Domen 